\title{
Synthèse des études hydrobiologiques réalisées en Loire moyenne au niveau du site nucléaire de Dampierre-en-Burly (France)
}

\author{
Hydrobiological studies at the level of the
}

Dampierre-en-Burly nuclear power plant in the course of the middle Loire (France)

\section{Nicole Lair ${ }^{(1)}$, Denis Sargos ${ }^{(2)}$ et Patricia Reyes-Marchant ${ }^{(3)}$}

(1) Université Blaise Pascal, UPRES A 6042, Géodynamique des milieux naturels et anthropisés 63177 Aubière Cedex (France)

(2) Université Blaise Pascal, UPRES A 6023, Biologie comparée des protistes, 63177 Aubière Cedex (France)

(3) UPRES A 6042, Bureau d'Etudes techniques des Milieux Aquatiques, EMA, La Croix Cadet, 63460 Jozerand (France)

Résumé. - Un état de référence, portant sur les variables hydrologiques et physicochimiques, la capacité autoépuratrice des eaux, la cartographie des groupements végétaux, la biomasse circulant dans ce secteur du fleuve ou inféodée aux fonds, a été dressé en 1977-1978. Indices de saprobies, indices diatomiques, indices biotiques, niveau typologique piscicole ont été définis au cours de ces deux années à hydrologie atypique. Ce secteur du fleuve, soumis à l'influence d'un bassin versant largement anthropisé est eutrophe.

A partir de 1979, un secteur amont et deux secteurs aval ont fait l'objet d'un programme de suivi écologique, basé sur 8 séries de prélèvements effectués chaque année entre avril et octobre, dont nous présentons une analyse chronologique basée sur une méthodologie évolutive (dont celle des indicateurs biologiques). Nous avons privilégié l'examen des tendances par le biais des moyennes mobiles. Le régime hydraulique reflète les variations climatiques où alternent années sèches (très productives) et années à forte hydraulicité (moins productives). Les débits influent largement sur la qualité biologique des eaux du fleuve, ce qu'illustre parfaitement l'analyse en composantes principales réalisée sur 104 séries d'observations recueillies en 13 ans. Température, $\mathrm{pH}$, MES augmentent de manière significative à l'aval immédiat du rejet, à l'inverse de la conductivité et des $\mathrm{NO}_{3}$; à la station située plus en aval l'augmentation de la teneur en $\mathrm{O}_{2}$ et en $\mathrm{SiO}_{2}$ est associée à une baisse de la teneur en $\mathrm{PO}_{4}$.

La microflore est bien diversifiée et bien structurée; la densité des microalgues atteint 
près de $250.10^{6}$ cell. $^{-1}$; ce sont les Chlorococcales qui dominent, suivies des Bacillariophycées dont la densité diminue dans le secteur le plus aval. Les Cyanobactéries sont peu abondantes. Les communautés benthiques de Bacillariophycées épilithiques atteignent une diversité spécifique particulièrement forte, témoin de leurs potentialités d'adaptation à ce type de milieu. Par période, les peuplements des supports artificiels s'avèrent déstructurés, contrairement à ceux des substrats naturels. Les suivis des indices IPS et CEC sur substrats naturels révèlent dans l'ensemble une eau de meilleure qualité en amont par rapport à l'aval. Les valeurs prises par les IQBG accusent de fortes fluctuations entre 1979 et 1986, puis elles deviennent plus stables, tandis que la diversité spécifique des Trichoptères augmente à partir de 1985, ces derniers s'avérant plus diversifiés dans le secteur de référence.

Outre les différences inhérentes aux variations climatiques, cette étude révèle des tendances à long terme sur cette partie du cours du fleuve: augmentation des valeurs de I'IPS et de la diversité spécifique des Trichoptères. Cette étude montre également des ruptures: changements spécifiques parmi les Bacillariophycées planctoniques à partir de 1986, stabilisation des variations des IQBG de 1987 à 1992, simultanément à la déstructuration du peuplement d'Ephéméroptères, déstructuration qui persiste jusqu'en fin d'étude.

L'influence de la centrale est à relier à la présence du seuil qui se situe en aval d'un secteur rectifié du fleuve, aux remous induits et aux variations locales de débit; les indices biotiques n'y sont pas sensibles, à l'inverse des indices diatomiques et des indices de diversité des Trichoptères qui permettent de détecter des différences amontaval. La complexité des processus mis en cause, dont l'hétérogénéité naturelle du milieu et les relations trophiques entre organismes, n'autorise pas à aller plus avant dans l'interprétation.

Mots clés. - Eaux courantes - état de référence - programme de sunveillance - variables hydrologiques et physico-chimiques - indicateurs biologiques.

Abstract. - Prior to an environmental monitoring program conducted from 1979 onward, the reference state was described in 1977-1978, in terms of hydrological, physical and chemical variables. The vegetation cartography, the capacity for water self-purification and the biomass circulating in this part of the river or confined at the bottom were studied. The saprobic, diatom and biotic indexes and the fish typology were calculated. This part of the river, largely anthropized upstream, is eutrophic.

Beginning in 1979, 8 series of samples were analyzed each year from April to October at the reference site situated upstream and at two downstream sites. A chronological analysis was performed to distinguish trends. The hydraulic regime reflects climatic variations between dry years (highly productive) and years of high hydraulicity (less productive). Discharge has a strong influence on the biological quality of the river, as illustrated by the Principal Component Analysis run on 104 data series over 13 years. A sill effect can be observed on the level of the dam: temperature, $\mathrm{pH}$ and suspended solids increase significantly immediately downstream of the release, contrary to conductivity and $\mathrm{NO}_{3}$. At the site further downstream, the increase in $\mathrm{O}_{2}$ and $\mathrm{SiO}_{2}$ is associated with a decrease in $\mathrm{PO}_{4}$.

The microflora was well diversified and well structured; the phytoplankton density reached $250.10^{6}$ cell. $^{-1}$ and was dominated by Chlorophytes and by Bacillariophytes. Few Cyanobacteria were found. The high species diversity of the epilithic diatoms illustrated their strong growth potential in that part of the hydrosystem. At times, the structure of diatom populations on artificial supports breaks down, which is not the case on natural substrates. Monitoring of IPS (index of specific sensitivity to pollution) and CEC indexes 
showed that water quality was generally better upstream than down. The strong fluctuations in IQBG values (index of general biological quality) observed from 1979 to 1986 contrast with more stable values from 1987 to 1992 . The species diversity of Trichoptera, highest at the reference site, increased from 1985 onward.

In addition to differences inherent to climatic variation, this studfy reveals the long-term trends in this part of the river: an increase in IPS values and in species diversity of Trichoptera. It also points up rupture: specific changes in planktonic Bacillariophytes beginning in 1986, stabilization in IQBG variations from 1987 to 1992, parallel to the breakdown of the diatom population which was observable through to the end of the study.

The influence of the power plant is more related to the presence of the dam and to the disturbances induced by its shelf. Unlike the biotic index, whose values remained constant both upstream and down, the diatom indexes and the indexes of species diversity of Trichoptera were more sensitive, revealing differences between upstream and downstream which cannot be fully explained by the complexity of the processes at work.

Key words. - Running waters, reference point, surveillance program, hydrological data, physico-chemical characteristics, biological indexes.

\section{INTRODUCTION}

Depuis la loi de protection de la nature du 10 juillet 1976 (décret du 12 octobre 1977), des études écologiques sont réalisées au droit des sites électronucléaires français. C'est ainsi qu'en Loire moyenne, les premières études sur le site de Dampierre-enBurly ont débuté en 1977, à la demande d'Électricité de France. Dans le contexte de l'époque, l'état du réseau hydrographique français était encore relativement peu suivi; outre la zonation des cours d'eau (Huet, 1954; Hynes, 1970; 1975), les outils d'étude dont nous disposions étaient limités à certaines composantes chimiques (Nisbet \& Verneaux, 1970), ou biologiques, dont l'utilisation des macroinvertébrés benthiques comme indicateurs de la qualité des eaux (Tuffery \& Verneaux, 1967). A l'époque, le fonctionnement global des écosystèmes d'eaux courantes était mal connu, les recherches s'étant surtout développées à partir des années 1980 (Vannote et al., 1980; Elwood et al., 1983) en même temps que l'on prenait conscience de l'impact de l'homme, ainsi les programmes d'études hydrobiologiques étaient-ils à concevoir (Lair et al., 1980).

Concernant plus particulièrement la Loire, en dehors de rapports internes rédigés par divers organismes d'état assurant, dans certains secteurs, la surveillance de la qualité de l'eau et celle du peuplement piscicole, nous disposions seulement de quelques publications anciennes sur la flore (Des Cilleuls, 1929; Amosse, 1932) ou plus récentes sur la faune (Aguesse, 1968; Pourriot et al., 1972). Ainsi avons nous cherché à dresser un état de référence le plus exhaustif possible, de manière à disposer de critères de choix en vue d'un futur suivi écologique, permettant de 
détecter d'éventuelles perturbations. Notre objectif fut le suivant : connaître le régime hydraulique des eaux et leur qualité physico-chimique avec une attention particulière pour la température, les matières en suspension et les paramètres indicateurs d'une activité biologique - connaître, au moyen d'analyses microbiologiques, les processus de dégradation de la matière organique accumulée et les capacités d'autoépuration de cette partie du fleuve - dresser une cartographie des groupements végétaux, estimer leur importance et les liens entre groupements, dont les hydrophytes indicateurs (Corillion, 1957), de manière à apprécier l'évolution saisonnière et naturelle à moyen terme - situer les divers niveaux de production, dont l'importance prise par la production primaire planctonique connaître la biomasse circulant dans ce secteur du fleuve - déterminer l'organisation saisonnière des communautés planctoniques et benthiques utiliser des indicateurs biologiques (indices de saprobies, indices diatomiques, indices biotiques) pour appréhender la qualité de l'eau et des indices de diversité permettant de détecter les modifications de la structure fonctionnelle de ces peuplements - réaliser enfin un inventaire piscicole. La centrale utilise les eaux du fleuve pour ses circuits de refroidissement et rejette certains produits de traitement, aussi le second objectif était-il le suivant: partant des maillons les plus importants du réseau alimentaire, détecter d'éventuelles perturbations dues au fonctionnement de la centrale, sans négliger les caractéristiques propres du fleuve et les processus naturels qui s'y déroulent.

\section{DESCRIPTION DU SITE}

La Loire, longue de $1012 \mathrm{~km}$, couvre un bassin versant de $117054 \mathrm{~km}^{2}$, représentant à lui seul $1 / 5^{\mathrm{e}}$ du territoire national. De par sa situation géographique, le fleuve est soumis à un régime nivo-pluvial; les variations climatiques imposent un régime hydraulique variable et des écarts de température conséquents. C'est dans le bassin supérieur, qui s'étend de la source jusqu'au bec d'Allier, que se rassemblent les eaux de montagne de la partie la plus élevée du Massif Central. La Loire y reçoit comme principal affluent l'Allier et un certain nombre de barrages, dont Poutès (1941), Grangeant (1956), ainsi que Naussac (1983) et Villerest (1988) qui contrôlent les débits minimum, y ont été aménagés. Des villes telles que Langeac, Brioude, Issoire, Clermont-Ferrand, Vichy, Moulins, ou Roanne jalonnent ce secteur amont Loire - Allier. Puis vient le bassin moyen dont le chenal couvre $300 \mathrm{~km}$ avant de recevoir les eaux du Cher, de l'Indre et de la Vienne qui s'y déversent plus en aval sur $30 \mathrm{~km}$ seulement. La ville de Nevers borde le fleuve après sa confluence avec l'Allier. C'est dans la partie amont de ce Val de Loire, à $550 \mathrm{~km}$ environ de la source du fleuve, que se situe Dampierre-enBurly (fig. 1). Jusqu'à Tours c'est un 


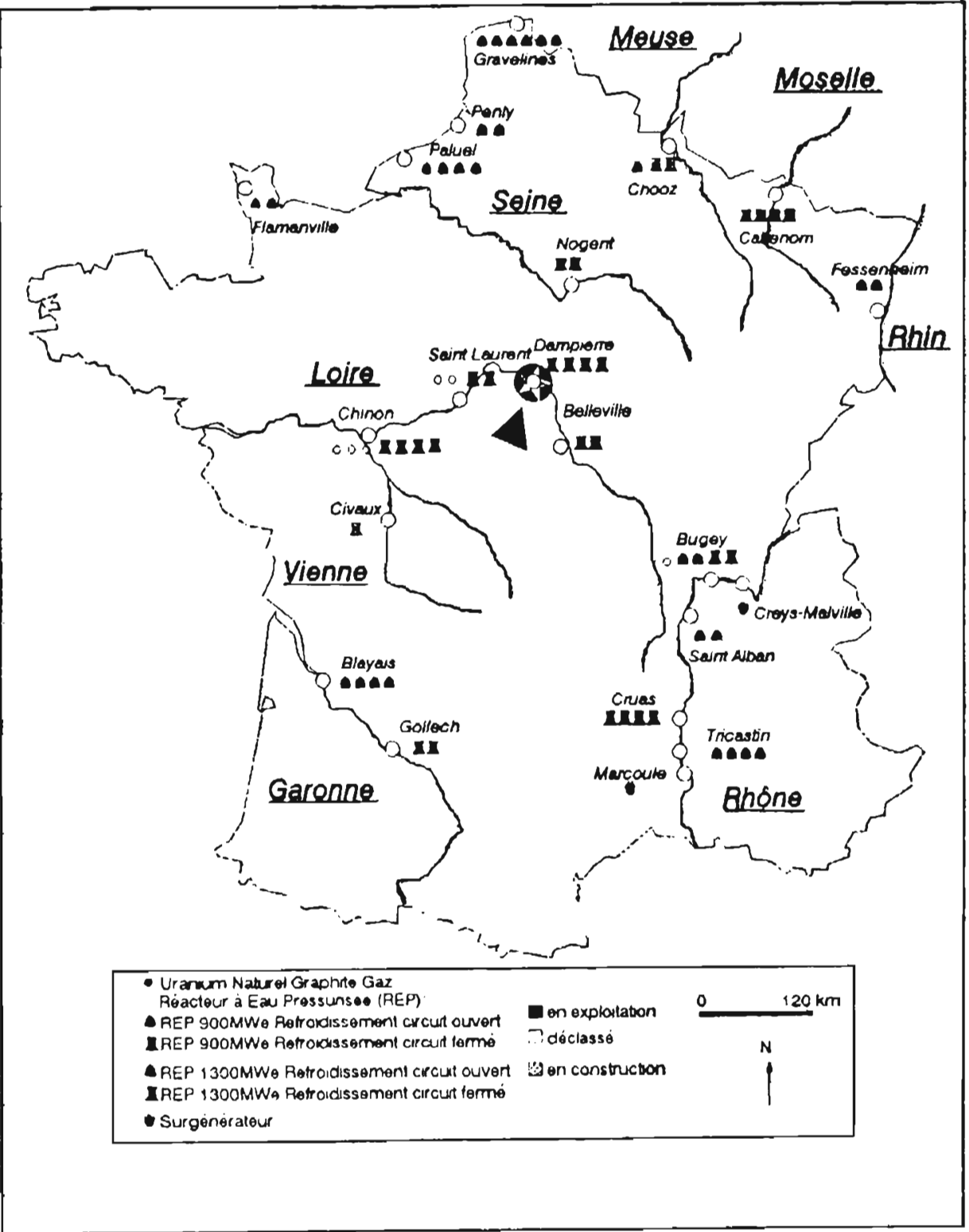

Fig. 1. - Centrales nucléaires françaises et situation du site de Dampierre-en-Burly dans le réseau hydrographique français.

Fig. 1. - Geographical location of the French nuclear power plants: Dampierre-en-Burly is the studied area. 
fleuve très irrégulier, encombré de bancs de sable pendant tout l'été, soumis à des crues de saison froide, liées à la fonte des neiges du Massif Central doublée d'averses, ou liées aux pluies persistantes d'automne. Des activités humaines de plus en plus importantes en jalonnent le cours, elles contribuent à l'enrichissement des eaux en éléments nutritifs et à une augmentation de la charge en éléments minéraux.

Dampierre-en-Burly à 123 mètres d'altitude, se situe à $15 \mathrm{~km}$ en aval de la ville de Gien, dans un secteur qui fut canalisé au XIX $\mathrm{X}^{\mathrm{e}}$ siècle; à ce niveau la largeur moyenne du fleuve est de 300 mètres environ. Un seuil, qui barre toute la largeur du fleuve en amont du site, a été aménagé pour permettre l'exploitation de la centrale; en amont de celui-ci le lit est resserré. De l'eau est dérivée vers le canal alimentant les tours de refroidissement (débit d'appoint) et les rejets de l'eau concentrée en sels dissous (débit de purge) diffusent au niveau de la digue. En période de basses eaux c'est une zone d'eaux calmes (fig. 2A). Immédiatement en aval la rivière méandre et des îlots parsèment le lit de place en place.

\section{Les stations d'étude}

Elles ont été choisies de manière à avoir un secteur de référence en amont, puis un secteur au niveau des rejets et un secteur plus aval, éloigné de leur influence directe. Le secteur amont, situé en rive gauche au lieu-dit "l'Ormette" a été échantillonné en 1977 et 1978 dans une zone à cou- rant faible à nul (faciès lentique) et dans une zone à courant rapide (faciès lotique). La station indiquée $3_{1}$ sur la carte et située dans le courant a servi de référence aux études ultérieures (fig. 2B).

A partir de 1979, deux stations aval ont été étudiées comparativement à cette station amont: la station $3_{2}$ a située en rive droite, en aval de la centrale, à $500 \mathrm{~m}$ du seuil, le long duquel se produisent les rejets et la station $3_{2} b$ située également en rive droite, susceptible de représenter un secteur aval analogue au secteur amont. Cette station fut d'abord située en amont du pont de Sully-sur-Loire, à $10 \mathrm{~km}$ environ; puis à partir de 1982, en raison de l'installation de stations automatiques de mesure, les échantillons ont été prélevés au droit de la station automatique EDF de Port-Ouzouer, située à $7 \mathrm{~km}$ en aval de la centrale.

\section{LES ÉTUDES ET MÉTHODES}

Dresser l'état de référence dans des milieux peu modifiés et peu pollués, état sans lequel il est impossible de suivre ensuite les éventuelles dégradations, n'est pas chose facile. II est en outre difficile de mesurer les influences respectives du cycle thermique, des teneurs en sels nourriciers ou en matières organiques, des conditions hydrodynamiques, ou des micropolluants sur les communautés vivantes, mais si l'un des composants est modifié, il y a des répercussions qualitatives et/ou quantitatives sur les 


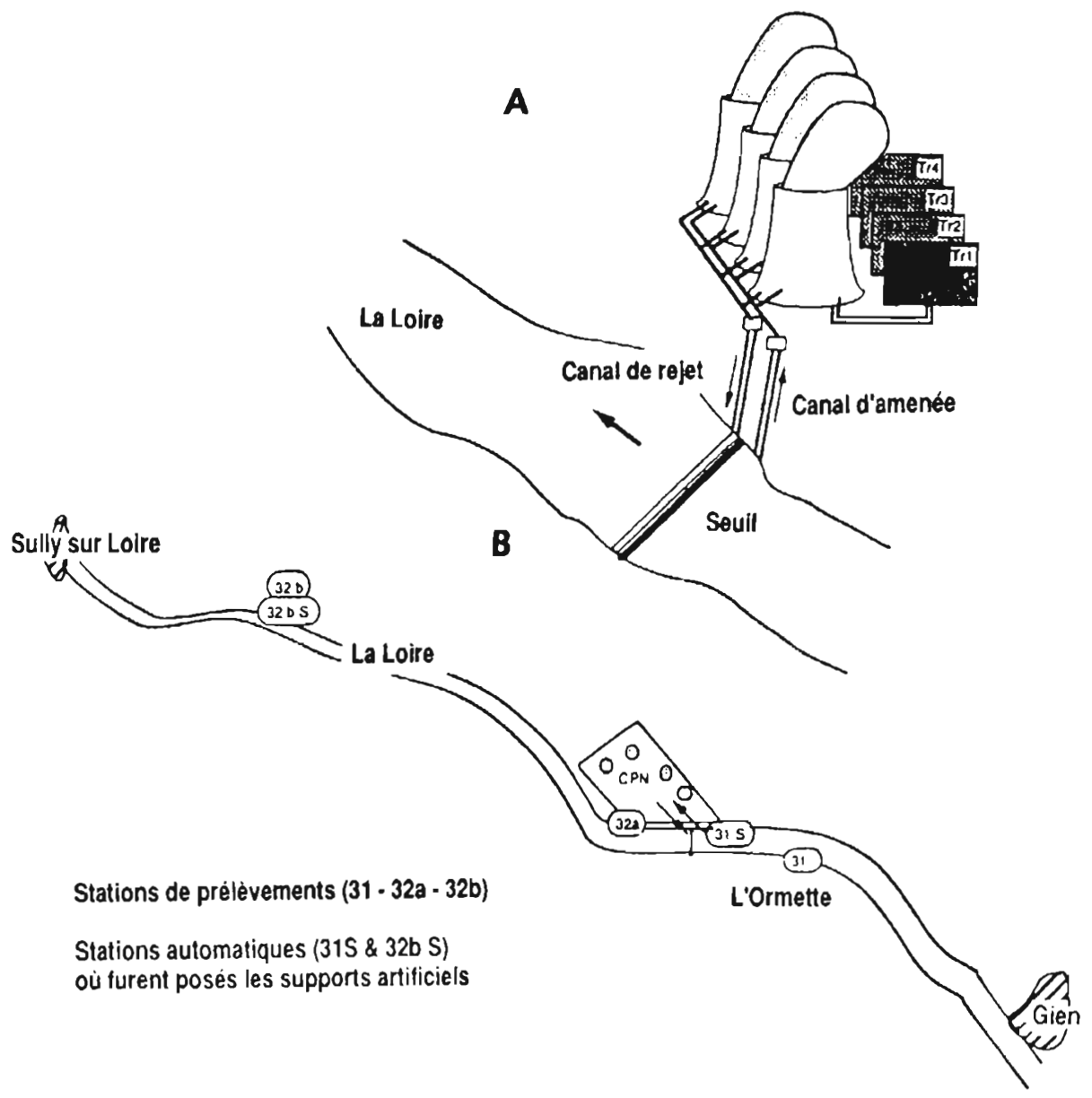

Fig. 2. - Schéma de fonctionnement de la centrale $(A)$ et situation des stations d'étude (B).

Fig. 2. - Diagram of the nuclear power plant functioning (A) and location of the sampling stations (B).

autres composants, y compris sur la qualité de l'eau. Le fleuve est en outre un milieu hétérogène par essence et les difficultés majeures consistent à obtenir des échantillons représentatifs.

L'état des lieux, effectué en 1977 1978, nécessitait des études pluridisciplinaires qui ont été réalisées par divers laboratoires de recherche spécialisés (Lair et al., 1980). Cet état de référence a consisté en l'étude de deux cycles annuels, à raison d'un prélèvement mensuel en période hivernale et de prélèvements bi- et trimensuels en période estivale (soit $19 \times 2$ séries de prélèvements).

En 1979, préalablement à la mise en service de la centrale, le site a été étudié sur une période plus courte (mai à décembre). A partir de 1980, 
les prélèvements nécessaires aux études de suivi écologique ont été répartis entre avril-mai et septembreoctobre, à raison de 8 échantillons par année. La disparité de ces deux types d'étude ne nous autorise pas à les prendre en compte selon une série continue, aussi traiterons nous des années 1977-1978 séparément, d'autant que les conditions climatiques de ces deux années étaient atypiques, comparativement à l'hydrologie moyenne. L'analyse chronologique débutera à partir de 1979.

Les différentes techniques utilisées par les laboratoires (dont les analyses physico-chimiques réalisées par le Service Régional d'Aménagement des Eaux d'Orléans) ont été consignées soit dans les rapports d'études, soit dans diverses publications (Lair, 1980; Lair \& Sargos, 1981; 1993). Ces méthodes en usage à l'époque, ont pour certaines bénéficié des progrès techniques et de l'avancement des connaissances au cours du temps, dont les méthodes inhérentes aux indicateurs biologiques. Pour l'analyse des microorganismes planctoniques, il a été procédé à la collecte d'échantillons moyens par secteur, composés d'un mélange d'échantillons d'eau prélevée sous la surface, sur un périmetre jugé représentatif du secteur étudié, au regard de ses caractéristiques hydrodynamiques; des études préliminaires avaient été réalisées sur le site de Saint-Laurent des Eaux en 1976 (Lair et al., 1978). Les microalgues benthiques ont été collectées sur des substrats naturels (épilithon) et, à titre comparatif de maniere à s'affranchir de
I'hétérogénéité du milieu, sur des lames de verre (lames à préparations microscopiques) qui permettent un échantillonnage quantitatif. Les macroinvertébrés ont été échantillonnés en référence aux protocoles correspondant aux indices choisis.

Avant de rappeler l'historique des méthodes pour lesquelles nous avons les plus longues séries de données, nous retiendrons qu'il a fallu attendre plus de 10 ans pour que les microalgues benthiques soient reconnues comme indicateurs fiables de la qualité des eaux des fleuves (Schoeman \& Haworth, 1986; Whitton et al., 1991). Des normes européennes sont apparues, des normes françaises sont en préparation. Quant aux techniques d'utilisation des macroinvertébrés comme indicateurs, celles-ci se sont sans cesse améliorées.

\subsection{Diatomées et indices diatomi- ques}

Les différentes espèces de Bacillariophycées ont des exigences écologiques propres et de ce fait sont sensibles à l'hydrologie, au substrat, à la lumière, à la composition chimique de l'eau, à la température etc. (Rott, 1991). Toute leur vie se passe dans l'eau, leur cycle de développement est très court, ce qui leur permet d'intégrer des changements instantanés de la qualité de l'eau (Descy \& Coste, 1988). Elles ont été regroupées en fonction de leurs affinités à des eaux de qualité différente et, au fur et à mesure des observations, les listes hiérarchisées des espèces ben- 
thiques (dans lesquelles le tychoplancton peut représenter une part importante), le chiffrage de leur qualité propre par rapport à une qualité globale, puis leur codage de manière à informatiser les données, illustrent l'évolution méthodologique que nous avons suivie au cours de ces études. Les pierres, sur lesquelles ont été recueillies les diatomées, représentent les substrats naturels les plus fréquents (Cazaubon et al., 1995); bien que la Loire soit un fleuve connu pour ses bancs de sable, nous avions choisi ces supports, beaucoup plus stables que les sables, dans la perspective de comparaisons à long terme. Nous avons exclu un recours systématique à la microscopie électronique et les listes de taxons ne prétendent pas être exhaustives, l'essentiel était de travailler dans les mêmes conditions de manière à procéder par comparaisons.

Les premiers indices avaient été fondés sur le système des saprobies (Pantle \& Buck, 1955), destiné à déterminer le niveau de pollution organique d'un milieu; leur application à l'étude des sites nucléaires nous avait parue d'autant plus importante que l'augmentation de la température des eaux provoque une augmentation de la production et donc de la quantité de matière organique. Puis des méthodes indicielles ont été développées en Belgique, sur la Meuse avec I'ID = indice diatomique (Descy, 1975), puis sur la Seine (Coste, 1978), puis dans le bassin RhôneMéditerranée-Corse, avec l'IPS $=$ Indice de Polluosensibilité Spécifique (C.E.M.A.G.R.E.F., 1982). Cet indice prend en compte toutes les espèces, quelles que soient leurs exigences écologiques (ubiquité) ou leur origine (planctonique ou benthique); il est valable pour toutes les régions de France. $\quad$ L'IDG = Indice Diatomique Générique (C.E.M.A.G.R.E.F., 1982; Rumeau \& Coste, 1988), basé sur l'utilisation des genres, a été proposé pour en faciliter l'utilisation; il comprend plus de 200 genres et a été revu, de manière à prendre en compte la nouvelle systématique proposée par Round et al. (1990).

L'Indice de Sladecek, proposé en 1987, correspondait à l'indice de Saprobie de Pantle \& Buck. Puis, le $\mathrm{CEC}=$ Indice de la Commission de la Communauté Européenne (Descy \& Coste, 1989), appelé également CEE a été conçu en référence aux études réalisées sur plus de 300 cours d'eau européens; très sensible aux variations de la composition des peuplements, il fait appel à 250 taxons environ. L'indice CEC que nous avons calculé est basé sur une grille de type indice biotique à deux entrées, 208 taxons sont pris en compte (espèces euryèces à sensibilité croissante et espèces sténoèces plus caractéristiques d'un niveau typologique de la rivière (I.D.E. Environnement, 1993). Une informatisation des données permet de calculer directement les différents indices (Coste, 1990).

Bien que certains taxons révèlent une préférence marquée pour certains substrats, les diatomées sont plus sensibles à la qualité de l'eau qu'à celle de l'habitat et dans le cadre des 
études d'impact des rejets d'eau chaude en milieu courant, où les stations échantillonnées sont hétérogènes, ceci prend toute son importance, d'autant que ces microalgues sont peu sensibles aux variations de débits. Des nombreuses études comparatives qui ont été réalisées, il ressort que les indices Sladecek et ID sont uniquement liés à la pollution organique, tandis que les indices IDG, IPS et CEC integrent davantage la qualité globale de l'eau (pollution organique, salinité et eutrophisation). Bien que nous ayons utilisé successivement ces différents indices, nous présenterons seulement dans ce travail les résultats des deux derniers qui s'avèrent les plus pertinents.

\subsection{Macroinvertébrés benthiques et indices biotiques}

De nombreux invertébrés d'eau douce, dont la taille est généralement supérieure au millimètre et qui appartiennent à divers groupes zoologiques, vivent au moins une partie de leur vie dans l'eau. Environ 125 familles, 700 genres et près de 3800 espèces ont été répertoriées en Europe et ont fait l'objet, depuis le début du siècle, de nombreuses recherches. Vivant à l'interface substrat/eau, ils en intègrent les altérations et leur distribution est fortement influencée par les caractéristiques de leur environnement, dont les divers substrats qu'ils colonisent et les pollutions. Par rapport aux diatomées, ces organismes mobiles peuvent être indicateurs d'une situation moins localisée, mais inversement, si le subs- trat ou la vitesse du courant changent, ils réagissent à ces modifications.

Comme pour les diatomées, les premières méthodes ont été basées sur le système des saprobies; elles ont débuté en Angleterre (Woodiwiss, 1964). En proposant leurs Indices Biotiques (IB), Tuffery \& Verneaux (1967) ont adapté la méthode anglaise aux eaux françaises en la reliant au mieux à l'écologie des invertébrés, selon un protocole d'échantillonnage précis. Au cours des années, ce dernier a été amélioré et successivement sont apparus les Indices de Qualité Biologique Globale (IQBG) et Potentielle (IQBP), ce dernier indice étant basé sur l'utilisation de supports artificiels (Verneaux \& Faessel, 1976; Verneaux, 1977) et pour lesquels la nature des habitats prospectés était plus précise. La première méthode normalisée, proposée en octobre 1985, accompagnée d'une autre procédure d'échantillonnage est celle de l'Indice Biologique Global (IBG). L'indice actuellement en vigueur est l'Indice Biologique Global Normalisé (IBGN) NF T 90-350 (1992), en référence à un nouveau protocole d'étude, assorti d'un guide technique (Gay, 1995); c'est celui que nous pratiquons depuis lors. Nous présenterons ici les résultats des IB et des IQBG, pour lesquels nous disposons d'une longue série de données. Ces indices biotiques sont plus stables dans le temps par rapport aux indices diatomiques, ils contribuent à donner une image plus optimiste de la qualité des eaux, en particulier lorsque les habitats sont diversifiés, mais ils traduisent mal les 
phénomènes d'eutrophisation marqués en période estivale, ainsi que les variations de la minéralisation (Coste, 1994).

\subsection{Indices de diversité}

L'étude des divers organismes étant accompagnée d'un inventaire systématique et d'une analyse quantitative, nous avons calculé l'indice de diversité de Shannon (Pielou, 1975) qui permet de déterminer, dans une communauté donnée, la place que prennent les taxons les uns par rapport aux autres et d'en suivre les variations (Magurran, 1988). Les indices de diversité ne sont pas liés au degré de pollution des eaux (Dam, 1982), mais ils permettent de détecter les variations de l'organisation des peuplements et leur utilisation revêt tout son intérêt dans le cadre de nos études comparatives amont-aval. Nous avons également réalisé des diagrammes rang fréquences (Frontier, 1976) qui permettent de visualiser les rangs pris par les différentes espèces et de suivre ainsi l'évolution spatiale et temporelle de leur ordre d'abondance; cette représentation graphique de la diversité des peuplements a l'inconvénient de demander beaucoup de place, nous citons cette technique pour mémoire.

\subsection{Traitement des données}

L'analyse de ces séries chronologiques a été réalisée par un calcul d'ordre 8 des moyennes mobiles (Wonnacott \& Wonnacott, 1991), de manière à visualiser graphiquement les tendances évolutives générales et à obtenir un guide d'interprétation des processus, y compris à long terme. Les moyennes mobiles sont centrées sur l'intervalle de temps considéré, ce qui explique l'absence de 4 valeurs au début et à la fin des séries figurées.

Après la saísie codée des espèces rencontrées, les indices diatomiques ont été calculés au moyen du logiciel COCAIINE (Coste, 1990). Une Analyse en Composantes Principales (Chessel \& Dolédec, 1993) a permis de visualiser les liens entre variables.

Les données amont/aval ont été soumises à l'épreuve du test non paramétrique de Wilcoxon, sur données appariées, de manière à déterminer si les différences observées sont significatives.

\section{RÉSULTATS DES ÉTUDES DE RÉFÉRENCE}

Ces études se sont déroulées au cours de 2 années climatiques atypiques, faisant suite à la sécheresse exceptionnelle de 1976, année durant laquelle l'étiage a duré jusqu'en décembre (le fait qu'un impôt national sécheresse ait été levé, témoigne de la sévérité des conditions climatiques qui régnèrent cette année là). L'année 1977 a été caractérisée par un régime de hautes eaux quasi permanent jusqu'en été 1978, suivi par un étiage qui s'est prolongé anormalement jusqu'en décembre 1978. 


\subsection{Qualité physico-chimique de l'eau}

Les caractéristiques physico-chimiques des eaux du fleuve, déterminées par le SRAE d'Orléans, ont reflété à la fois les variations du régime hydraulique et celles de l'activité saisonnière des organismes photosynthétiques. Température, $\mathrm{pH}, \mathrm{O}_{2}$ dissous, oxydabilité, $\mathrm{DBO}_{5}$, azote ammoniacal et nitreux présentaient un maximum en période de basses eaux, en relation avec la production algale (>0,60 g C. $\mathrm{h}^{-1}$ en été). L'étiage prolongé de 1978 a eu pour conséquence une augmentation de la minéralisation de l'eau du fleuve qui, rappelons le, se trouvait en situation anormale par rapport au débit de référence. Conductivité, alcalinité, teneurs en calcium, magnésium, sulfates, chlorures, sodium et potassium ont atteint de fortes valeurs à partir d'octobre, tandis que le faible ensoleillement et la baisse de température conjointe, ralentissaient la production végétale. La densité algale a atteint $160.10^{6}$ cell. $^{-1}$ et les éléments nutritifs nécessaires à la croissance des algues (avec des minimums et des maximums respectifs de $0,05 \mathrm{mg} . \mathrm{l}^{-1}$ et $0,42 \mathrm{mg} . \mathrm{l}^{-1}$ pour les phosphates et de 0,15 et $13,6 \mathrm{mg} \cdot \mathrm{I}^{-1}$ pour les nitrates) n'ont pas été épuisés totalement, ce que nous avons régulièrement constaté au cours des études suivantes. Les teneurs en chlorophylle a atteignaient $140 \mu \mathrm{g}^{-1}{ }^{-1}$, ces valeurs sont comparables à celles qui seront mesurées dans ce secteur en 1987 (Oudin, 1990), témoignant du caractère eutrophe de cette partie du fleuve. Des valeurs $>200 \mu \mathrm{g} . \mathrm{I}^{-1}$ seront mesurées en 1979. A titre indicatif, dans le cours inférieur du Rhin, en 1981 des valeurs maximales de $100 \mu \mathrm{g}^{.} \mathrm{l}^{-1}$ de chlorophylle (et des densités de $62.10^{3}$ cell. ml $^{-1}$ ) et en 1990 des valeurs maximales de $140 \mu \mathrm{g}^{-1}$ de chlorophylle (et des densités $>60.10^{6} \mathrm{cell} . \mathrm{ml}^{-1}$ ) ont été mesurées (Friedrich \& Viehweg, 1984; Admiraal et al., 1994). Pour mémoire, des études réalisées sur les sédiments par le Centre de Recherches Géodynamiques de Thonon-les-Bains ont révélé les difficultés, inhérentes aux fonds meubles de la Loire, à retenir ce type de matériel pour détecter un impact.

\subsection{Qualité microbiologique}

L'étude microbiologique, réalisée par le Laboratoire de Microbiologie de I'Université de Bordeaux I, a montré que le fleuve était doué, au niveau du site, d'un pouvoir autoépurateur efficace, aboutissant à une minéralisation correcte de la matière organique, sans consommation excessive d'oxygène et que le lessivage du bassin versant alimentait pour une large part la microflore du fleuve. En pleine eau, les variations de la microflore autochtone (Pseudomonas putida, $P$. fluorescens, Acinetobacter sp., Flavobacterium sp. et Bacillus sp.) reflètent les variations du régime hydrologique. Les densités atteignent $4,3.10^{4}$ germes. $\mathrm{ml}^{-1}$, tandis que les formes sporulées ont une remarquable constance numérique, les valeurs 
les plus faibles des formes végétatives étant mesurées en étiage. Les éléments fongiques sont moins bien représentés. Dans la microflore additionnelle, les mésophiles suivent les variations de la microflore autochtone, passant en moyenne de $6,0.10^{3}$ à $1,6.10^{3}$ germes. $\mathrm{ml}^{-1}$ de la période de hautes eaux à la période de basses eaux. La microflore fécale (Escherichia coli, Citrobacter sp., Enterobacter $\mathrm{sp}$., Klebsiella sp.) révèle un apport permanent de déjections d'origine animale et humaine; elle chute en étiage également, à l'exception des Clostridium sulfito-réducteurs, en raison là encore de la faible part jouée par le lessivage des sols du bassin versant en période de faible hydraulicité. Enfin, la flore accidentelle se résume à des bactériophages spécifiques de Salmonella sp. et de Shigella sp., suggérant la présence de ces bactéries.

Dans les sédiments, la microflore totale représente en moyenne $2.10^{6}$ germes. $\mathrm{g}^{-1}$ de sédiment frais et suit la même tendance que celle de la microflore de l'eau, bien que le métabolisme de certaines souches ne puisse être comparé. Leur polyvalence augure très favorablement le bon état d'équilibre de ce milieu aquatique. Parmi les bactéries sporulées Bacillus cereus mycoides a fréquemment été détecté. Les champignons (Aspergillus sp. et Penicillium sp.) existent en nombre toujours élevé et la baisse de densité se retrouve en étiage. L'examen des groupements physiologiques qui assurent les réactions biochimiques inhérentes au cy- cle de l'azote dénote un bon déroulement des processus de fixation, ammonification, nitrification et dénitrification (avec recrudescence des processus de réduction). Pour le cycle du carbone, les bactéries cellulolytiques aérobies (peu nombreuses), anaérobies (plus importantes) et amylolytiques (quantités élevées) s'adaptent constamment aux conditions du milieu. Quant au cycle du soufre, les germes responsables de la sulfatoréduction assurent leur fonction, ils sont plus nombreux en étiage.

De ces deux années aux conditions hydrologiques particulières, nous retiendrons que les micropopulations offrent un judicieux équilibre d'espèces autochtones qui accomplissent une autoépuration efficace, et qu'une partie de la microflore circulante est largement véhiculée par les eaux météoriques.

\subsection{Examen floristique}

L'étude de la végétation macrophytique, réalisée par le laboratoire de Biologie végétale et de Phytogéographie d'Angers, a été menée dans des secteurs où l'influence de l'homme est peu marquée, dans le but de suivre son évolution au cours des années à venir et d'établir des comparaisons amont-aval. Presque toutes les espèces végétales qui constituent, dans les conditions normales, l'armature des associations typiques du Val de Loire ont pu être recensées. Les groupements végétaux des deux rives ont permis de caractériser les niveaux in- 
férieurs (lit mineur), les niveaux moyens (basses pentes des rives, dépressions) et les niveaux supérieurs (hautes pentes de rives et terrasses).

En rive droite, la végétation du site offre un ensemble de 14 types de groupements végétaux, parmi lesquels la forêt alluviale à saulnaie buissonnante en bordure de rive (Salix purpurea, Salix viminalis), à saulnaie arborescente sur la rive principale (Salix alba), mêlée à la peupleraie à Populus nigra et aux stades pré-forestiers à Crategus monogyna, Prunus spinosa, Ulmus campestris, Quercus pedunculatus (situés sur les buttes intercalées entre les dépressions humides). Ces groupements végétaux sont associés à des boisements mixtes au nord du site (frênaie-ormaie-chênaie, mêlée à la saulnaie ou à l'aulnaie).

Les friches, pelouses et prairies tantôt bien développées, tantôt fragmentaires ont été affectées par le relèvement du niveau de l'eau au voisinage du seuil; parmi les 7 groupements caractéristiques de cet ensemble, citons les végétations de grands hélophytes qui apparaissaient dispersées, atypiques (Carex sp., Scirpus sp.) et les groupements d'hydrophytes localisés dans le chenal central, avec des éléments de la prajrie submergée (Potamogeton crispus, Ceratophyllum demersum, Myriophyllum apicum). Le tapis végétal du site de l'Ormette offrait de nombreuses analogies avec les végétaux de la rive droite, le site était cependant plus boisé et sa composition s'enrichissait, par exemple, des Salix triandra et $S$. atrocinerea; il n'y avait pas d'hydrophytes.

De ce bilan réalisé en 1978 il est ressorti qu'en rive droite, le dynamisme de la végétation a été perturbé par le relèvement du niveau des eaux en amont du seuil de la centrale. Sous l'angle des régressions, les végétations des niveaux inférieurs et de la basse rive en ayant déjà subi le choc, cela présageait de changements ultérieurs peu importants. Sous l'angle progressif, divers groupements végétaux devaient pouvoir reconstituer leurs populations (grands hélophytes, hydrophytes etc.); les végétations les plus favorisées demeuraient celles des friches herbeuses et des prairies à Agropyrum repens. Parmi les groupements des niveaux inférieurs, l'association Cyperus michelianus Cyperus fuscus - Ilysanthes attenuata, par son contact plus étroit avec le milieu aquatique, offrait une valeur particulière comme indicateur de modifications écologiques. A l'Ormette, l'édification du barrage n'ayant pas perturbé le dynamisme de la végétation, ce sont l'association précédente et l'association à Bidens tripartita Polygonum sp., présentes sous forme de liserés de rive qui ont été considérées comme indicateurs de modifications écologiques. Comme conséquences futures il était prévu le resserrement de la zonation sur les rives, avec réduction du caractère mésoxérophile ou xérophile de certains groupements, soumis à de nouvelles conditions écologiques, le rôle subtil de l'évolution et de la concurrence propres à la végétation ne de- 
vant cependant pas être perdu de vue. Qu'en est-il en 1995?

Absentes de la partie amont des cours d'eau, où les forts courants font obstacle à leur développement, les communautés planctoniques trouvent des conditions de développement favorables dans la partie moyenne des fleuves où la turbidité ne limite pas encore la production primaire. Concernant le phytoplancton, nous avons observé le schéma classique de développement suivant: aux $\mathrm{Ba}$ cillariophycées printanières ont fait suite les Chlorophycées estivales, qui ont été remplacées à l'automne par de nouvelles populations de Bacillariophycées (Lair \& Sargos, 1981). Cette étude a continué dans le cadre du suivi (Lair \& Reyes-Marchant, en préparation).

\subsection{Examen faunistique}

Les Protozoaires Ciliés, étudiés par le laboratoire de Protistologie de I'Université de Clermont-Ferrand, ont senvi de base au calcul des indices de saprobie. Les 17 (1977) et 12 (1978) espèces indicatrices répertoriées mensuellement, soit dans l'eau, soit au niveau des sédiments, révèlent une eau de qualité satisfaisante, particulièrement en 1978. Des espèces $\alpha$ polysaprobes, mêlées à des espèces $\alpha$ mésosaprobes, révèlent cependant un milieu riche en matières organiques.

Le plancton animal est classiquement dominé par des Rotifères dont la prolifération est favorisée par le développement des communautés planctoniques algales et bactériennes qui leur servent de nourriture. Comme celui des algues, le développement des rotifères est fonction du régime hydraulique du fleuve : faible richesse spécifique et faible densité en période de hautes eaux (dont l'année 1977), diversification et prolifération en période d'étiage. Les crustacés sont demeurés très rares et réduits à quelques stades de développement (Lair \& Sargos, 1981). Des espèces cosmopolites telles que Asplanchna spp., Brachionus calyciflorus, B. angularis, B. bennini, B. quadridentatus, $B$. urceolaris, Filinia longiseta et $F$. terminalis, Keratella cochlearis et sa forme tecta, $K$. quadrata et sa forme valga. Polyarthra spp., Synantherina socialis (forme benthique) abondent dans les eaux. Ces organismes sont d'excellents indicateurs de la qualité des eaux et, dans les centrales avec rejets d'eaux chaudes, situées en aval de Dampierre-en-Burly, nous avons observé le développement plus précoce en amont, ou plus tardif en aval, de certaines espèces, en fonction de leurs exigences thermiques (Lair, 1980).

Ces communautés ne seront plus étudiées de 1979 à 1995, dans la mesure où cela aurait nécessité des prélèvements à la fois plus précoces et plus tardifs dans la saison pour suivre leur ordre d'apparition et de disparition dans le temps. Cependant, avec l'avancement des connaissances sur la dynamique fluviale, soulignons qu'en raison de la densité qu'ils peuvent atteindre (en 1978 nous avions

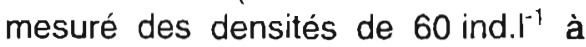


Dampierre-en-Burly, en 1995 nous

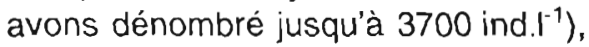
ces organismes pour la plupart filtreurs contribuent par leur broutage à la régulation des communautés bactériennes et algales et au transfert de la production vers les niveaux supérieurs. Leur présence en plus ou moins grande quantité en amont et en aval (effet de seuil et surtout présence de zones lentiques dans les secteurs non rectifiés) peut être cause de variations de la densité algale, comme c'est le cas dans les eaux lacustres eutrophes (Lair \& Oulad Ali, 1990) et comme nous avons pu le vérifier au cours de l'étude réalisée en 1995 sur les sites de Dampierre-en-Burly et de Saint-Laurent-des-eaux (Lair \& Reyes-Marchant, 1996). Dans le cours inférieur du Rhin, ces organismes ont des densités moyennes de 200 ind. $^{-1}$ et des valeurs atteignant

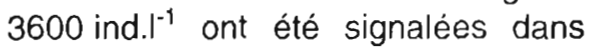
des eaux courantes où leur rôle fonctionnel nécessiterait d'être mieux connu, d'autant que ces organismes sont un aliment de choix pour les jeunes alevins (Winner, 1975; ReyesMarchant, 1993; Admiraal et al., 1994).

Bien que souvent difficiles à collecter dans le lit mineur des fleuves, les communautés animales benthiques de macroinvertébrés, dont l'étude a été confiée au SRAE d'Orléans, servent de nourriture à la majeur partie des poissons, pendant au moins une partie de leur vie. Elles ont permis de vérifier que la qualité de l'eau était nettement moins bonne en période d'étiage. Les IQBG ont atteint des va- leurs de 17 en juin 1977 et de 16 en mars 1978, pour prendre des valeurs de 9 à 11 en octobre et décembre 1977. En référence à la typologie proposée par Verneaux (1977), notons la présence des Heptagenia sulphurea et Potamanthus luteus (typologie de type $\mathrm{B}_{8}$ ) et des Polymitarcys virgo (typologie de type $B_{9}$ ). Leur examen sera poursuivi au cours du suivi écologique.

Les poissons, également étudiés par le SRAE d'Orléans, ont été capturés au moyen de divers engins de pêche. En raison des conditions hydrologiques les nasses se sont révélées les plus efficaces en 1977, tandis que les pêches électriques ont pu être pratiquées de manière efficiente seulement en 1978 et en rive gauche, là où les habitats étaient les plus diversifiés. II conviendra de garder en mémoire que cet inventaire demeure partiel, en raison de la sélectivité des engins de pêche et du choix des secteurs, imposé par le niveau des eaux. En 1977 le barbeau (Barbus barbus) s'est avéré dominant; en 1978 une association brême (Abramis brama), hotu (Clondrostoma nasus), chevesne (Leuciscus cephalus), puis gardon (Rutilus rutilus) et barbeau a été observée. La répartition des classes d'âge traduisant une mortalité importante de juvéniles et d'individus $1+$, est à mettre en relation avec l'étiage exceptionnel de 1976 et avec les hautes eaux de 1977. En référence aux facteurs mésologiques (Verneaux, 1977) le niveau typologique serait de 7,54 (gamme repère $=S A 6$, diversité $=19$, gamme typologique $B_{8} B_{9}$, type 
écologique $B_{9} B_{8}$ ), avec poissons chat (Ictalurus melas), brêmes et sandres (Sander lucioperca) comme espèces repères. Dans le cadre du programme de surveillance, l'étude de la faune ichtyologique n'a pas été poursuivie.

\section{SURVEILLANCE ÉCOLOGIQUE : RÉSULTATS}

Nous avons privilégié l'étude des producteurs benthiques (associée à celle des producteurs planctoniques, en raison de la présence d'un abondant tychoplancton), et celle des consommateurs benthiques (ces derniers étudiés par le SRAE d'Orléans). Ces organismes qui colonisent les fonds sont soumis aux contraintes de leur environnement dont ils reflètent la qualité. Leur étude a été réalisée en référence aux variations de débit et aux variations de la composition physico-chimique des eaux, analysée au SRAE d'Orléans.

Nous disposions, à partir de 1979 , de séries temporelles facilement comparables car, sous réserve des variations climatiques interannuelles, les dates de prélèvement étaient sensiblement les mêmes. Nous avons privilégié les analyses synthétiques, permettant de voir les tendances, au détriment des analyses fines qui sont davantage le reflet de l'hétérogénéité naturelle du milieu ou de la flexibilité des organismes. Nous indiquerons pour mémoire les valeurs extrêmes, les illustrations porteront sur les moyennes mobiles, privilégiant les tendances.

\subsection{Variables abiotiques}

\subsubsection{Débits}

L'amplitude des variations de débit est très importante, les crues printanières (dont le débit mesuré au niveau de Gien peut être ponctuellement supérieur à $2000 \mathrm{~m}^{3} \cdot \mathrm{s}^{-1}$ ), sont fréquentes. Durant les périodes de basses eaux le débit pouvait descendre en dessous de $50 \mathrm{~m}^{3} . \mathrm{s}^{-1}$ avant que les étiages ne soient maintenus à un niveau minimum de $60 \mathrm{~m}^{3} \cdot \mathrm{s}^{-1}$ grâce au soutien des retenues de Naussac et Villerest mise en service à partir de 1983 et 1988. Les années 1982, 1989, 1990 et 1991 ont été marquées par une faible hydraulicité, due à une période d'étiage précoce et longue. Les débits extrêmes correspondant aux dates des campagnes de prélèvements étaient de $48 \mathrm{~m}^{3} \cdot \mathrm{s}^{-1}$ et de $771 \mathrm{~m}^{3} \cdot \mathrm{s}^{-1}$. Les années 1985,1986 , 1987, 1988, 1990, 1992 (année à étiage peu prononcé, suivi de crues), 1993 et 1994 ont été marquées par de fortes eaux de printemps, des étiages tardifs et souvent courts (fig. 3). Les caractéristiques hydrauliques font de la Loire un fleuve très "typé" et les débits ont une influence très importante sur la qualité biologique du fleuve (Lack, 1971; Decamps \& Naiman, 1989; Moss \& Balls, 1989; Lair \& Sargos, 1993).

\subsubsection{Régime thermique naturel (sta- tion amont)}

Le maximum estival a atteint $27,6^{\circ} \mathrm{C}$ et le minimum est tombé à $7,8^{\circ} \mathrm{C}$. Nous avons là une illustration de la variabilité climatique classique- 
ment rencontrée en climat continental; cette variabilité peut se manifester non seulement d'un jour à l'autre, mais au cours d'une même journée. Une amplitude journalière de $7,5^{\circ} \mathrm{C}$ a été enregistrée sur le site en août 1980. Sur la période printemps-automne la température moyenne est de $19^{\circ} \mathrm{C}$ à la station située en amont.

\subsubsection{Régime thermique aval}

Cette centrale fonctionne en circuit fermé, le débit d'eau de purge échauffée rejeté par l'intermédiaire des crépines le long du seuil est d'environ $1 \mathrm{~m}^{3} \cdot \mathrm{s}^{-1}$ pour chaque tranche (cf. fig. 2A). Ce rejet est destiné à éviter la concentration des sels dissous dans le circuit de refroidissement, if peut contenir des produits de lavage (chlorations périodiques), et sa température est supérieure à celle du mi- lieu récepteur. L'examen des moyennes mobiles (fig. 3), montre que les valeurs amont-aval se recouvrent, quelle que soit l'année. L'augmentation de température observée en 1983 est la résultante d'une variation saisonnière de très faible amplitude et de fortes températures printanières et automnales.

Au site de Dampierre-en-Burly, sur la période 1979-1994, les mêmes minimums $\left(7,8^{\circ} \mathrm{C}\right)$ ont été mesurés aux 3 stations. De l'amont à l'aval, les maximums estivaux ont été respectivement de $27,6^{\circ} \mathrm{C}, 28,7^{\circ} \mathrm{C}$ et $27,8^{\circ} \mathrm{C}$ (mesures ponctuelles de température effectuées au dessous de la surface de l'eau, au moment des prélèvements). Depuis 1984, le régime saisonnier de la température est relativement stable. Les tendances révèlent une légère augmentation de

Tableau I. - Valeurs minimale, moyenne et maximale des variables physico-chimiques. Résultats du test de Wilcoxon des valeurs appariées (ns = non significatif).

Table I. - Minima, mean and maxima values of the different physico-chemical variables and Wilcoxon test (paired data, with $\mathrm{ns}=$ non significant).

\begin{tabular}{|c|c|c|c|c|c|c|c|c|c|c|c|c|c|}
\hline & & $\begin{array}{l}\text { Desbit } \\
\text { mis: }\end{array}$ & $\begin{array}{l}\text { Conduct } \\
\mu S . c m\end{array}$ & $\begin{array}{l}\text { DBO5 } \\
\text { mgl. }\end{array}$ & $\begin{array}{l}\text { MES } \\
\text { mg.l }\end{array}$ & $\begin{array}{l}\overline{\mathrm{NH4}} \\
\mathrm{mg.l}\end{array}$ & $\begin{array}{l}\mathrm{NO3} \\
\mathrm{mg} .1\end{array}$ & $\begin{array}{l}\text { O2 dis } \\
\text { mg.l }\end{array}$ & $\begin{array}{c}\text { Oxydab } \\
\text { mg.l }\end{array}$ & $\mathrm{pH}$ & $\begin{array}{l}\text { PO4 } \\
\text { mg.l : }\end{array}$ & $\begin{array}{l}\text { Silice } \\
\text { mg.l }\end{array}$ & $\begin{array}{c}\text { Temp } \\
\mathrm{C} \\
\end{array}$ \\
\hline \multirow[t]{4}{*}{31} & mınımum & 48 & 151 & 13 & 54 & 0.006 & 0.5 & 7.6 & 0.7 & 7.4 & 0.02 & 0.5 & 78 \\
\hline & maxımum & 771 & 348 & 10.1 & 1430 & 0345 & 14.5 & 20.1 & 71 & 3.7 & 0.60 & 15.0 & 27.6 \\
\hline & moyenne & 181 & 233 & 5.2 & 29.8 & 0.038 & 41 & 12.2 & 3.3 & 8.7 & 0.18 & 6.7 & 19.2 \\
\hline & ecart type & 144 & 35 & 2.3 & 16.3 & 0.041 & 3.2 & 2.7 & 0.9 & 0.6 & 0.12 & 3.2 & 3.8 \\
\hline \multirow[t]{4}{*}{$32 a$} & minimum & $\cdots$ & 140 & 11 & 48 & 0010 & 04 & 8.0 & 0.8 & 73 & 0.02 & 0.5 & 7.8 \\
\hline & maximum & - & 337 & 190 & 1170 & 0.125 & 13.0 & 17.8 & 79 & 9.8 & 0.49 & 14.7 & 28.7 \\
\hline & moyenne & - & 230 & 5.2 & 327 & 0.028 & 8.9 & 12.0 & 3.3 & 8.7 & 0.16 & 6.7 & 19.3 \\
\hline & Gcart type & - & 35 & 23 & 156 & 0023 & 3.0 & 2.1 & 10 & 0.6 & 0.11 & 3.1 & 3.9 \\
\hline \multirow[t]{4}{*}{326} & minimum & - & 142 & 0.9 & 48 & 0010 & 0.5 & 79 & 0.9 & 73 & 0.02 & 0.5 & 7.8 \\
\hline & maximum & $\cdot$ & 320 & 9.5 & 128.0 & 0.150 & 144 & 21.2 & 76 & 9.6 & 0.52 & 15.0 & 27.6 \\
\hline & moyenne & $\cdots$ & 233 & 5.0 & 27.3 & 0.027 & 40 & 12.7 & 32 & 8.7 & 0.14 & 6.9 & 19.3 \\
\hline & ecart type & - & 35 & 2.0 & 16.6 & 0024 & 3.1 & 2.6 & 0.9 & 0.6 & 0.11 & 3.0 & 3.9 \\
\hline \multicolumn{2}{|c|}{ Test de Wilcoxon } & & Conduct. & DBO5 & MES & NH4 & NO3 & 02 dis. & Oxydab. & $\mathrm{pH}$ & $\mathrm{PO} 4$ & Silice & Temp. \\
\hline \multirow{2}{*}{\multicolumn{2}{|c|}{$\begin{array}{l}\text { amont - aval a } \\
\text { amont - avad b } \\
\text { aval a - aval b }\end{array}$}} & & $p<0.01$ & ns & $p<0.001$ & $p<0.001$ & $p<0.001$ & ns & ns & $p<0, \infty 01$ & $p<0.001$ & $p<0,01$ & $p<0,001$ \\
\hline & & & $\begin{array}{c}\text { ns } \\
p<0.01\end{array}$ & $\begin{array}{l}p<0.001 \\
p<0.001\end{array}$ & $\begin{array}{l}p<0.001 \\
p<0.001\end{array}$ & $\begin{array}{c}p<0.001 \\
n s\end{array}$ & $\begin{array}{c}n s \\
p<0.001\end{array}$ & $\begin{array}{c}p<0.01 \\
p<0.001\end{array}$ & $\begin{array}{l}\text { ns } \\
\text { ns }\end{array}$ & $\begin{array}{c}p<0,05 \\
n g\end{array}$ & $\begin{array}{l}p<0.001 \\
p<0.01\end{array}$ & $\begin{array}{l}p<005 \\
p<0001\end{array}$ & $\begin{array}{c}\text { ns } \\
<0.01\end{array}$ \\
\hline
\end{tabular}




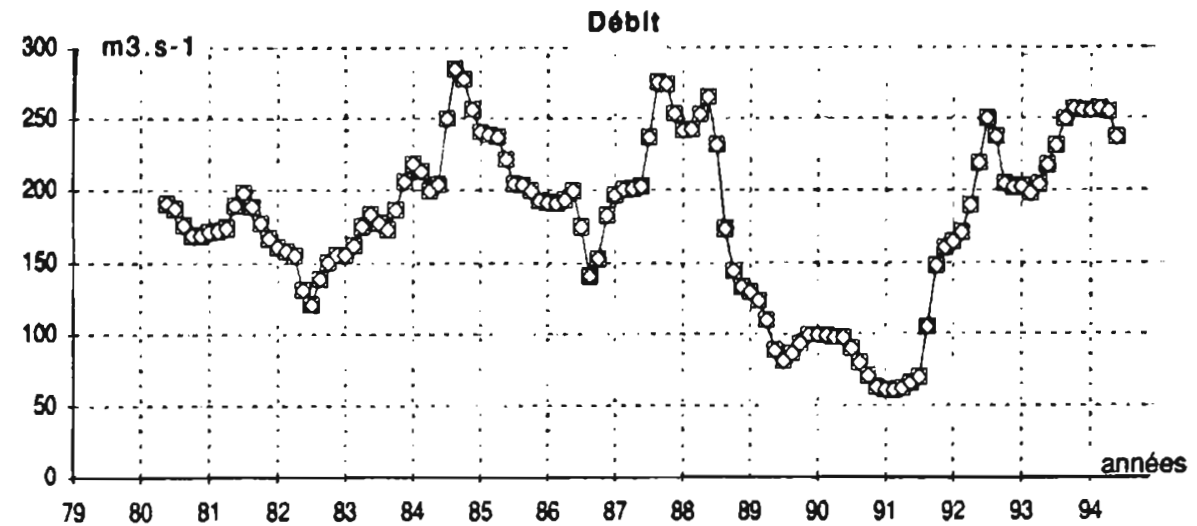

Température
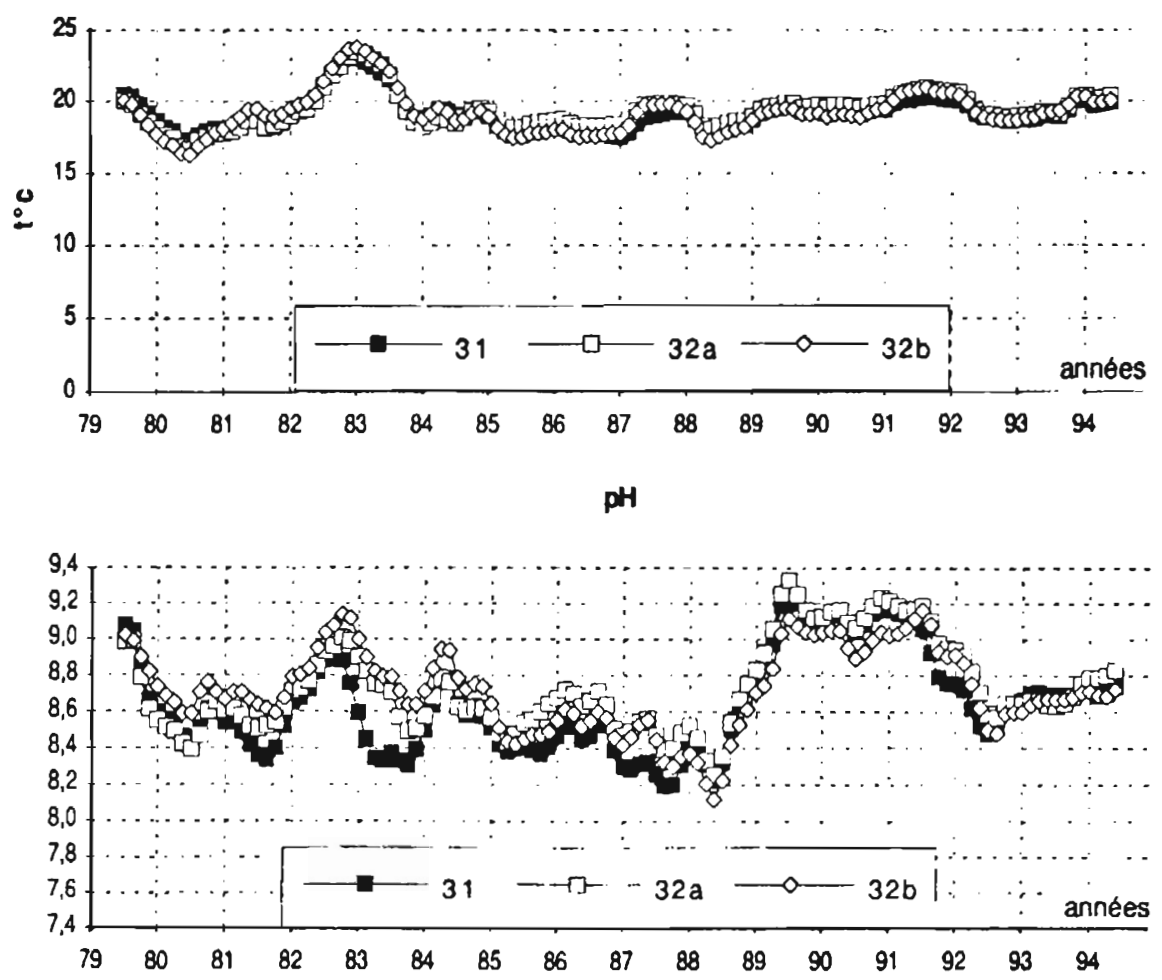

Fig. 3. - Variations des débits, de la température et du pH (moyennes mobiles) aux stations amont $\left(3_{1}\right)$, aval immédiat $\left(3_{2} a\right)$ et aval éloigné $\left(3_{2} b\right)$.

Fig. 3. - Variations in flow, temperature and $\mathrm{pH}$ measured upstream $\left(3_{1}\right)$, immediately after the power plant $\left(3_{2} \mathrm{a}\right)$ and more downstream $\left(3_{2} \mathrm{~b}\right)$. 
température à l'aval immédiat du rejet, tendances confirmées par le test de Wilcoxon $(p<0,001$, tab. I).

\subsubsection{Variations $d u p H$}

En amont, les valeurs de $\mathrm{pH}$ qui ont été mesurées durant la période considérée étaient comprises entre 7,4 et 9,7 . Les fortes valeurs estivales sont liées à l'activité photosynthétique, en 1982 et au cours des trois années sèches 1989, 1990 et 1991, les faibles débits ont induit une plus forte concentration des éléments nutritifs provenant de l'amont. Ceci associé avec un ensoleillement important a favorisé la croissance des microalgues; en conséquence l'activité photosynthétique a provoqué une augmentation $\mathrm{du} \mathrm{pH}$ dont les valeurs oscillaient entre 9,0 et 9,5. Notons qu'un $\mathrm{pH}$ de 9 est la limite supérieure de tolérance pour la plupart des espèces de poissons (Nisbet \& Verneaux, 1970).

En aval également, les valeurs observées sont très proches les unes des autres (fig. 3). Les maximums ont été relevés en période estivale, avec respectivement d'amont en aval 9,79,8 et 9,6 unités $\mathrm{pH}$. Les périodes de fort $\mathrm{pH}$ sont généralement associées à de fortes températures et à de faibles débits : ceci est particulièrement net en 1982 et de 1989 à 1991. La Loire est déjà un fleuve très productif au site de Dampierre-en-Burly. Une légère augmentation de $\mathrm{pH}$, significative, se manifeste à l'aval immédiat du rejet; le test de Wilcoxon donne une probabilité $<0,001$ (tab. I).

\subsubsection{Matières en suspension}

Les eaux charrient des matières de taille microscopique d'origine détritique, terrestre ou sédimentaire, et des microrganismes en suspension (MES). Nous avons relevé des valeurs comprises entre 4,8 et $143 \mathrm{mg}^{-\mathrm{I}^{-1}}$. Les valeurs moyennes mesurées en amont $\left(29,8 \mathrm{mg} \mathrm{I}^{-1}\right)$ sont inférieures à celles mesurées à l'aval immédiat du rejet $\left(32,7 \mathrm{mg}^{-1} \mathrm{l}^{-1}\right)$. En période de basses eaux, les MES sont en majorité dues aux populations planctoniques, comme l'indique un rapport MES / biomasse algale voisin de 1 (fig. 4). Par contre en période de hautes eaux elles sont essentiellement liées au matériel détritique véhiculé par les forts débits, le rapport MES / biomasse algale est en effet supérieur à 5 . La représentation des moyennes mobiles montre clairement l'augmentation des MES au niveau du rejet, illustrant l'importance des effets de remous au niveau du seuil; ceci est confirmé par le test de Wilcoxon $(p<0,001)$. Cet effet s'annule quelques kilomètres plus loin (fig. 5).

\subsubsection{Teneurs en oxygène dissous}

Les variations journalières de ce paramètre sont très importantes, en liaison non seulement avec les variations de température qui se produisent au cours du nycthémère, mais surtout en fonction des variations de l'activité photosynthétique. Nous avons mesuré des valeurs extrêmes de 7,6 mg..$^{-1}$ (site amont) et 21,2 mg..$^{-1}$ (site aval éloigné). En période estivale les eaux sont sursaturées en oxy- 


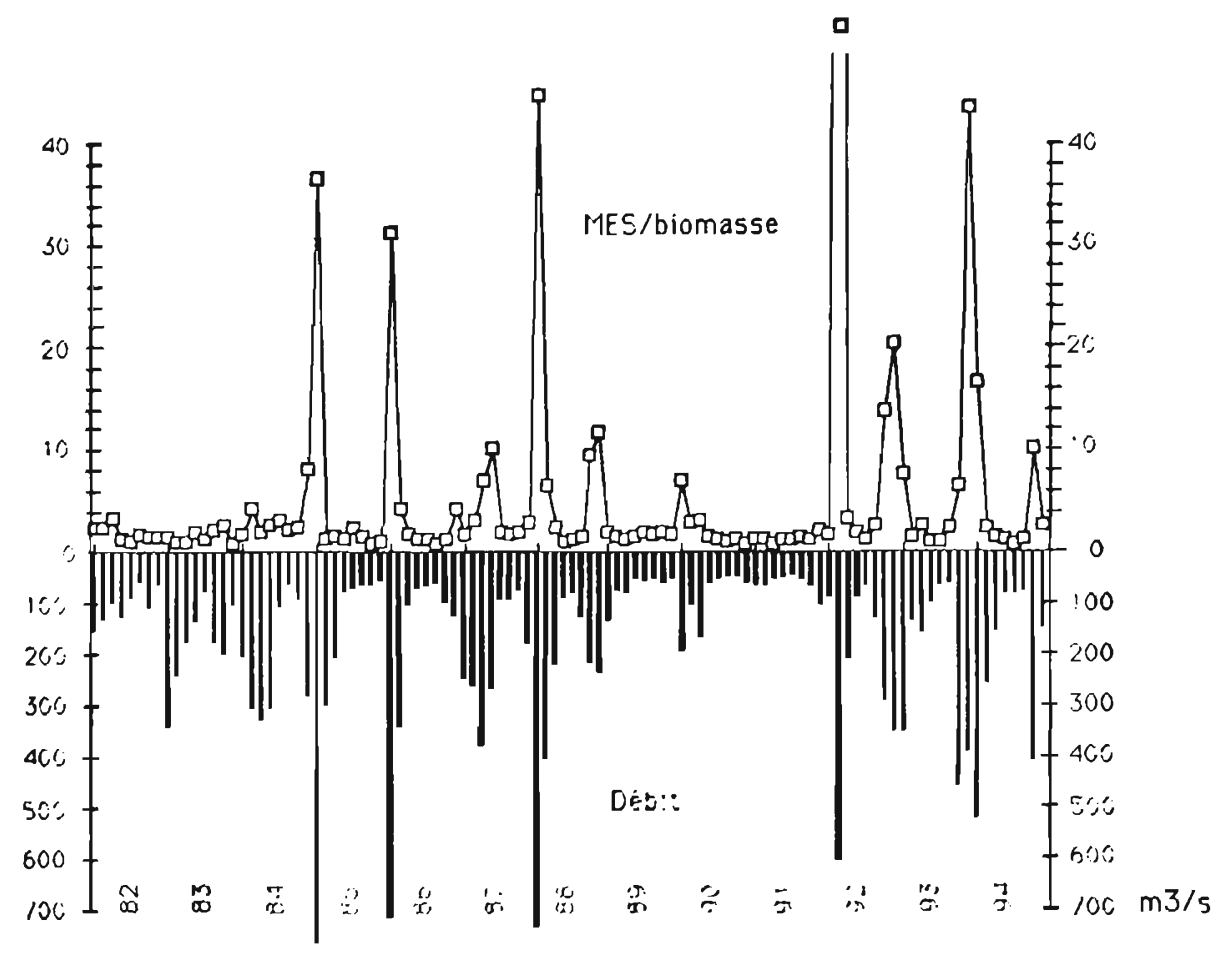

Fig. 4. - Variations du rapport MES/biomasse algale et du débit.

Fig. 4. - Variations in flow and SM/algal biomass values.

gène, confirmant en cela la capacité autoépuratrice de l'eau dans cette partie du fleuve, mais aussi le caractère eutrophe du milieu. Durant la période de basses eaux la sursaturation est quasi permanente et les variations nycthémérales sont très grandes, comme nous avons pu le constater au vu des enregistrements en continu réalisés sur le site. Les valeurs moyennes sont de $12,02 \mathrm{mg} . \mathrm{l}^{-1}$ en amont, très proches à la station $3_{2} \mathrm{a}$ $\left(12,0 \mathrm{mg}^{-1}{ }^{-1}\right)$ et un peu plus fortes à la station $3_{2} b\left(12,7 \mathrm{mg}^{-1}{ }^{-1}\right)$, avec des différences significatives à une probabilité de $p<0,01$ (fig. 5, tab. I).
5.1.7 Demande biologique en oxygène dissous ( $\mathrm{DBO}_{5}$ )

Les valeurs extrêmes varient de 0,9 à $11,0 \mathrm{mg}^{-1} \mathrm{l}^{-1}$. En été, la $\mathrm{DBO}_{5}$ est dépendante de la biomasse phytoplanctonique: les plus fortes valeurs estivales sont observées lors des années à développement algal important (années 1980, 1989, 1990 et 1991). Globalement, les variations de ce paramètre suivent une tendance inverse à celle de l'oxygène dissous, à l'exception des années de sècheresse (1989 à 1991) où les processus de production l'ont emporté. Les phéno- 


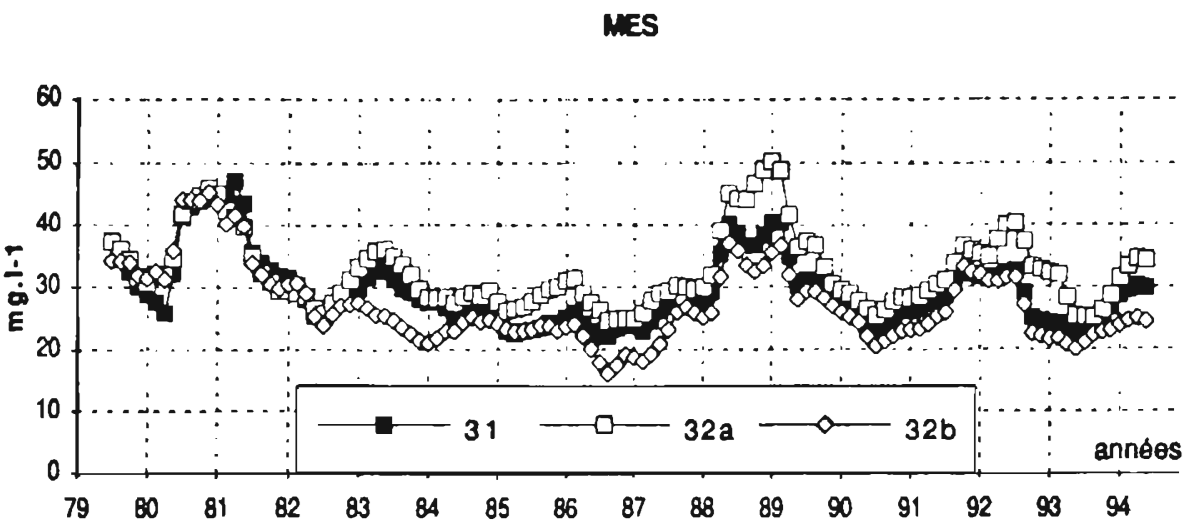

\section{Oxygène dissous}

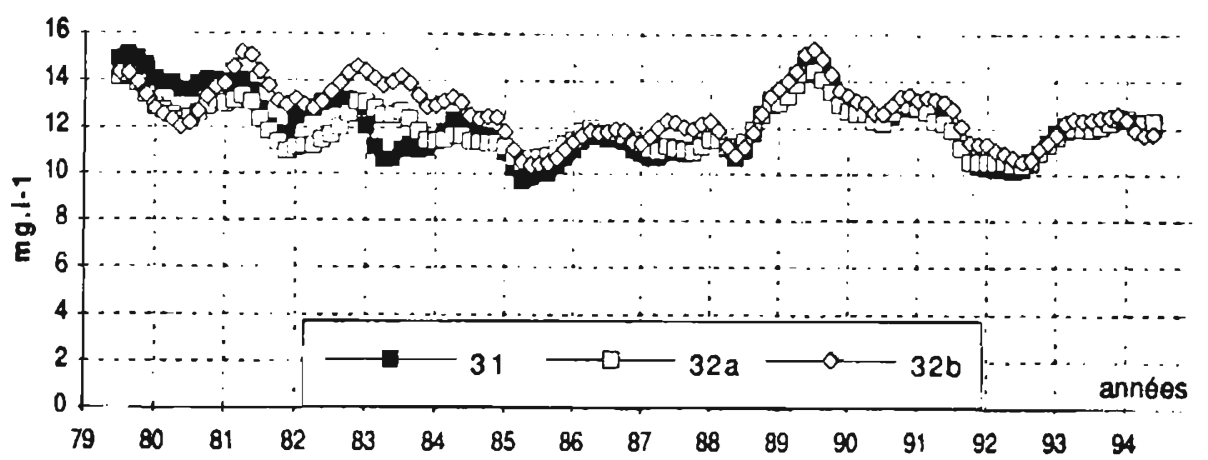

DBO

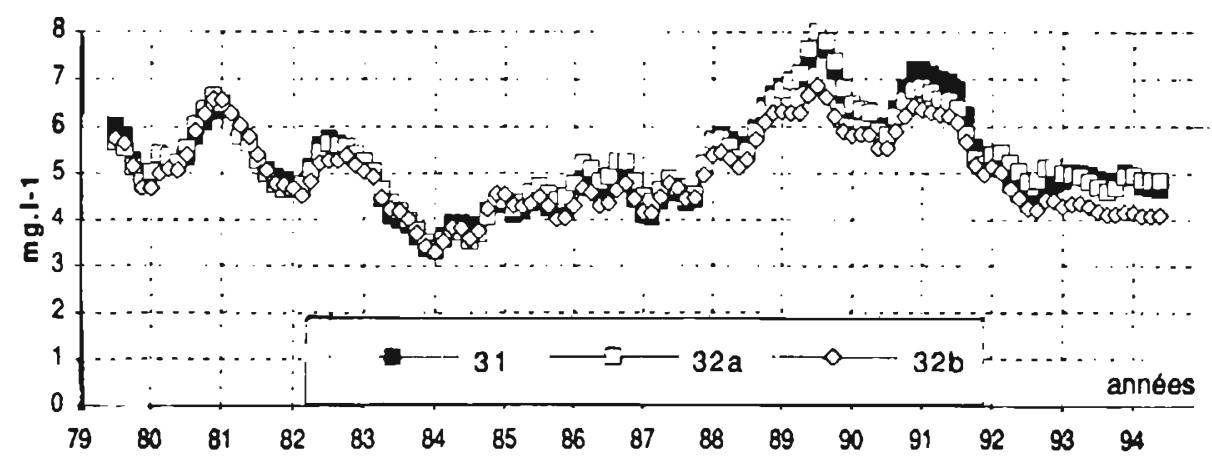

Fig. 5. - Variations des teneurs en matieres en suspension et en oxygene dissous, et variations de la $\mathrm{DBO}_{5}$ (moyennes mobiles) aux stations amont $\left(3_{1}\right)$, aval immédiat $\left(3_{2} \mathrm{a}\right)$ et aval éloigné $\left(3_{2} \mathrm{~b}\right)$. Fig. 5. - Variations in $\mathrm{SM}$, dissolved oxygen and $\mathrm{BOD}_{5}$ values (moving averages), measured upstream $\left(3_{1}\right)$, immediately after the power plant $\left(3_{2} a\right)$ and more downstream $\left(3_{2} b\right)$. 
mènes de décomposition sont accentués au niveau du rejet et s'atténuent en aval. L'examen des variations d'ensemble des moyennes mobiles permet de mettre en évidence une tendance à une diminution de la $\mathrm{DBO}_{5}$ de 1981 à 1984 suivie d'une augmentation de 1985 à 1989 et d'une diminution progressive à partir de 1991 (fig. 5). Ces variations cycliques sont directement liées à l'hydraulicité, facteur prépondérant du développement de la biomasse algale. Les valeurs moyennes de la $\mathrm{DBO}_{5}$, qui oscillent autour de 5,2 mg. $\mathrm{l}^{-1}$, indiquent que les eaux présentent une qualité douteuse; les variations entre les stations amont et aval $3_{2}$ a ne sont pas significatives, elles le sont entre amont et aval $3_{2}$ b (tab. I).

\subsubsection{Oxydabilité}

Les valeurs observées en amont et en aval oscillent entre $0,7 \mathrm{mg}^{-\mathrm{l}^{-1}}$ et $7,9 \mathrm{mg} \cdot \mathrm{l}^{-1}$, elles sont restées stables durant les années 1984 à 1986, années à régime hydrologique normal, en référence à la typologie que nous avons établie (Lair \& Sargos, 1993). Les moyennes mobiles sont proches (fig. 6), avec des valeurs de $3,3{\mathrm{mg} . \mathrm{I}^{-1}}^{-1}$ $-3,3 \mathrm{mg} . \mathrm{l}^{-1}$ et $3,2 \mathrm{mg.} \mathrm{J}^{-1}$ respectivement aux trois stations; il n'y a pas de différence significative (fig. 6 , tab. I).

\subsubsection{Conductivité}

La conductivité de l'eau, dont les valeurs varient de 140 à $348 \mu \mathrm{s} . \mathrm{cm}^{-}$ 1 , augmente avec la teneur en sels électrolysables dissous dans l'eau et varie en fonction de la température. Les plus fortes valeurs enregistrées correspondent aux plus faiblesvaleurs des débits (fig. 6). De l'amont à l'aval les valeurs moyennes sont successivement de $233 \mu \mathrm{s} . \mathrm{cm}^{-1}, \quad 230 \mu \mathrm{s} . \mathrm{cm}^{-1} \quad$ et $233 \mu \mathrm{s} . \mathrm{cm}^{-1}$. Les moyennes mobiles illustrent bien l'augmentation de la minéralisation durant les années de sécheresse (1982 et 1989 à 1991). La conductivité diminue à l'aval immédiat du rejet, la différence est significative à $p<0,01$ (tab. l). Est-ce dû aux conséquences des remous qui se produisent au niveau du seuil? l'effet s'annule plus en aval.

\subsubsection{0 Éléments nutritifs et silice}

L'assimilation de l'azote par les végétaux et l'incidence de l'hydraulicité sont à l'origine des variations des composés azotés qui ne sont pas limitants (e.g. Lair \& Sargos, 1993). Des teneurs d'azote ammoniacal $\left(\mathrm{NH}_{4}^{+}\right)$, supérieures à $0,12 \mathrm{mg} \cdot \mathrm{l}^{-1}$, ont été mesurées entre 1983 et 1986, ainsi qu'en 1989 et 1993 (maximum atteint: $0,34 \mathrm{mgl}^{-1}$ ). La valeur guide de qualité requise à la vie des poissons n'est pas propice aux salmonidés, ce sont des eaux cyprinicoles (directive européenne). De fortes variations de ce paramètre sont perceptibles sur les moyennes mobiles (fig. 6), les valeurs sont souvent plus fortes en amont (la différence est significative à $p<0,001$, tab. I); dans l'ensemble, elles sont demeurées à un niveau plus faible à partir de 1987. Les concentrations en nitrites $\left(\mathrm{NO}_{2}^{-}\right)$ sont toujours inférieures à $0,1 \mathrm{mg} . \mathrm{l}^{-1}$, nous ne les avons pas figurées.

Les teneurs en nitrates $\left(\mathrm{NO}_{3}^{-}\right)$peuvent atteindre exceptionnellement des 


\section{Oxydabilite}

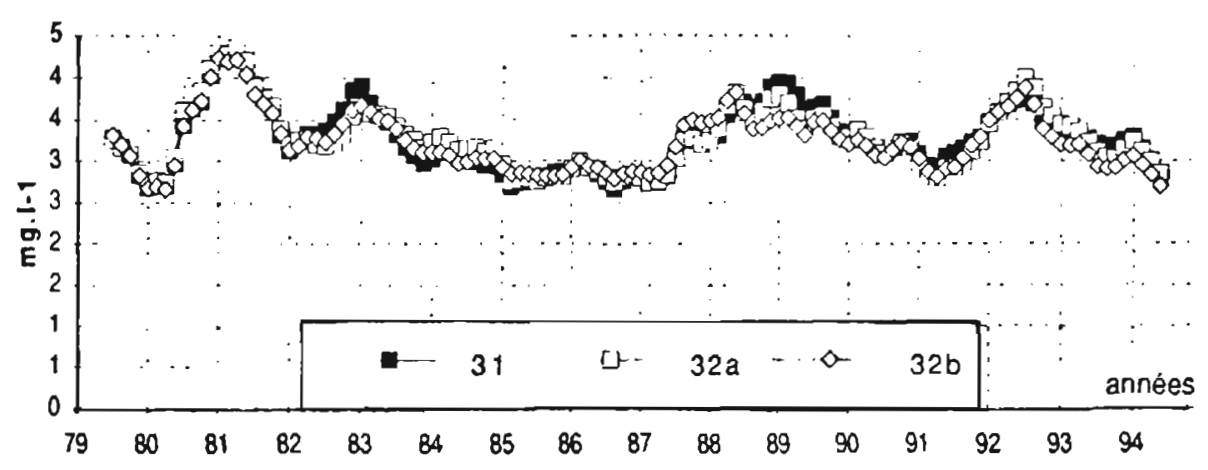

\section{Conductivité}

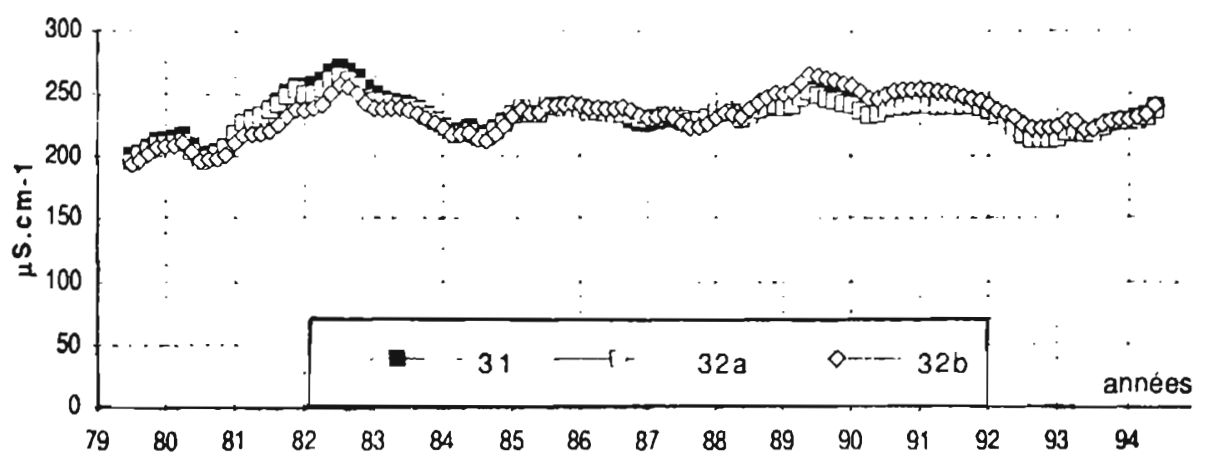

NH4

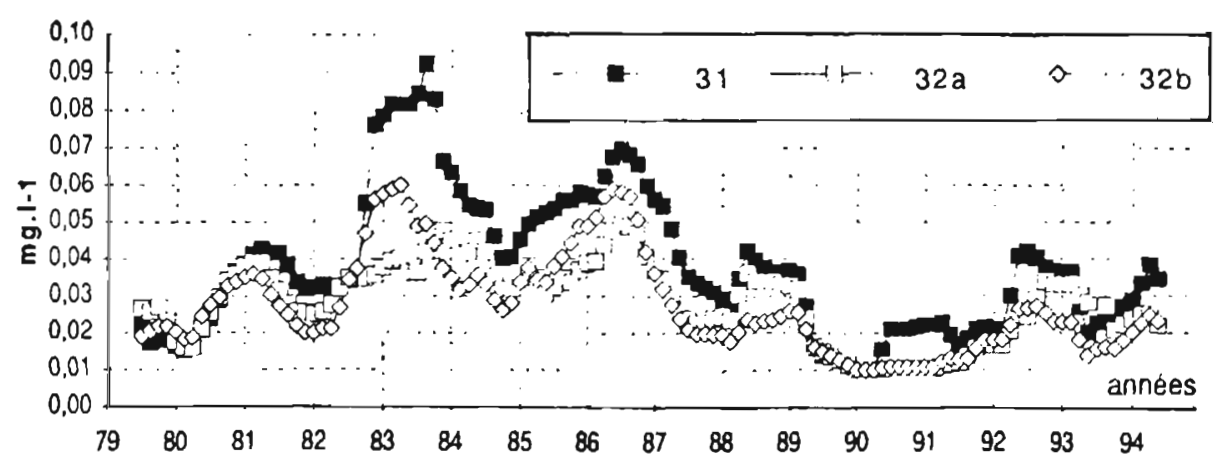

Fig. 6. - Variations de l'oxydabilité, de la conductivité et de l'ammoniaque (moyennes mobiles) aux stations amont $\left(3_{1}\right)$, aval immédiat $\left(3_{2}\right.$ a) et aval éloigné $\left(3_{2} b\right)$.

Fig. 6. - Variations in oxydability, conductivity and ammoniac values (moving averages), measured upstream $\left(3_{1}\right)$, immediately after the power plant $\left(3_{2} a\right)$ and more downstream $\left(3_{2} b\right)$. 
NO3

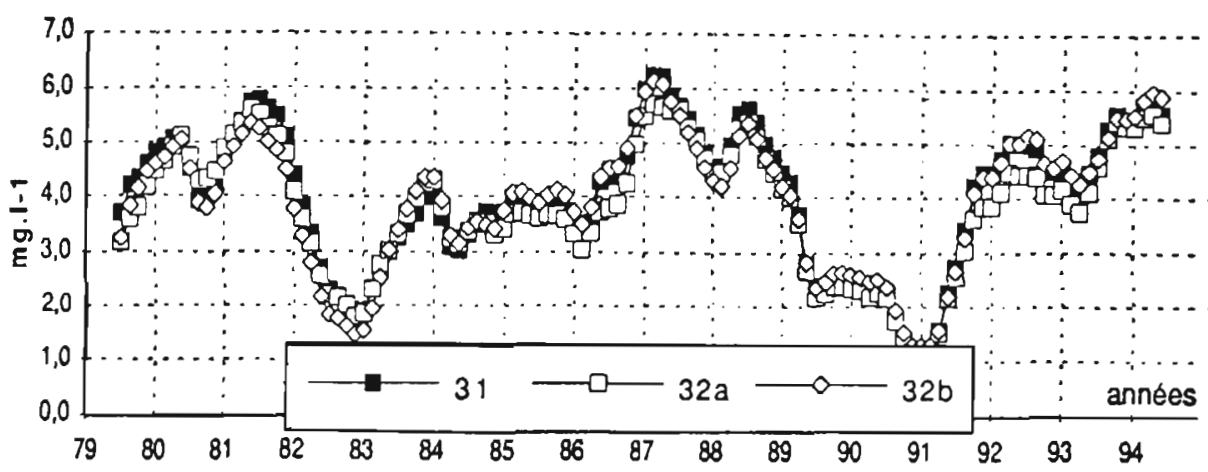

P04

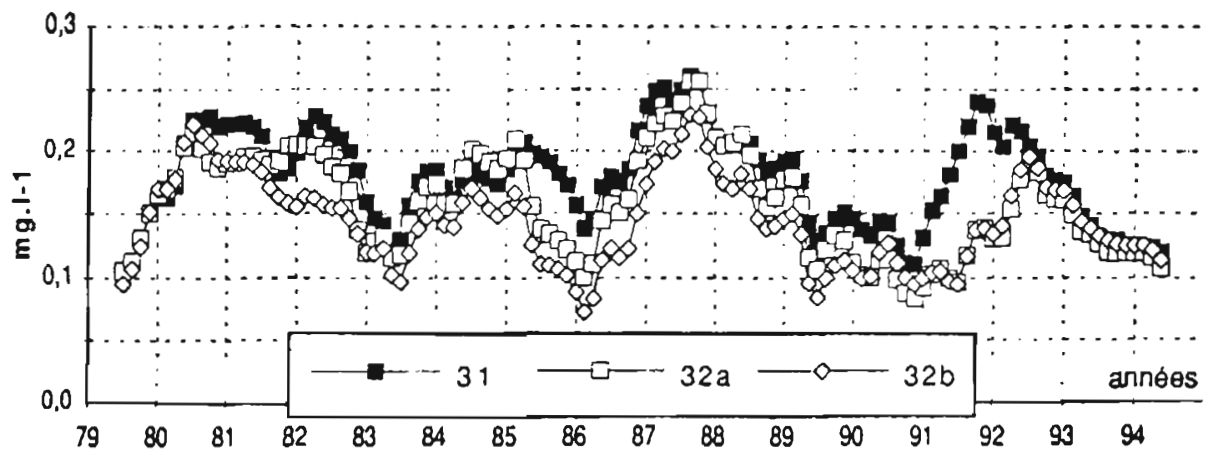

Silice

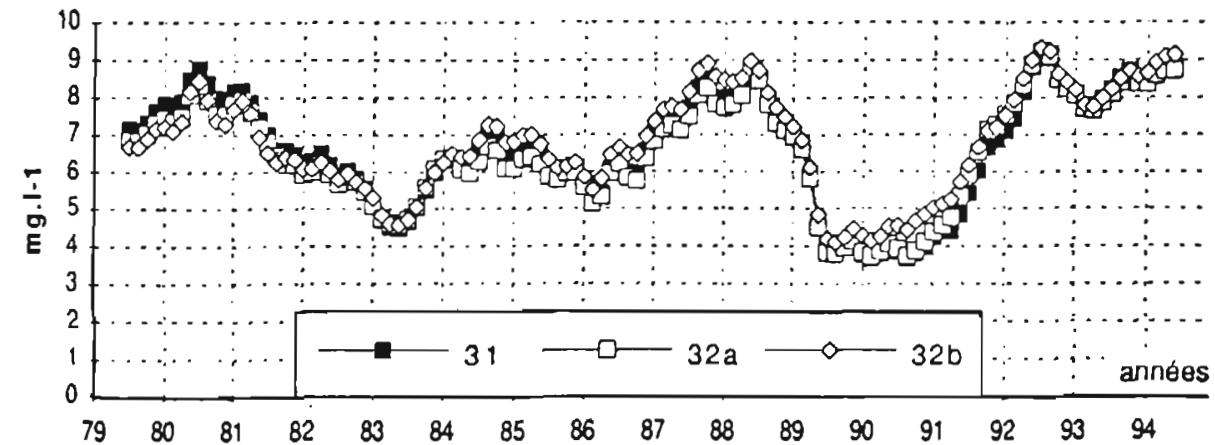

Fig. 7. - Variations des teneurs en nitrates, phosphates et silice (moyennes mobiles) aux stations amont $\left(3_{1}\right)$, aval immédiat $\left(3_{2} a\right)$ et aval éloigné $\left(3_{2} b\right)$.

Fig. 7. - Variations in nitrate, phosphorus and silica values (moving averages), measured upstream $\left(3_{1}\right)$, immediately after the power plant $\left(3_{2} a\right)$ and more downstream $\left(3_{2} b\right)$. 
valeurs proches de $15,0 \mathrm{mg} . \mathrm{I}^{-1}$; elles témoignent de la productivité moyenne à forte de ce secteur du fleuve. Les valeurs moyennes passent de $4,1 \mathrm{mg} . \mathrm{l}^{-1}$ en amont à 3,9 mg. $\mathrm{I}^{-1}$ et $4,40 \mathrm{mg} \cdot \mathrm{I}^{-1}$ en aval, elles sont très proches aux trois stations (fig. 7). Les moyennes mobiles illustrent la consommation de cet élément les années de faible hydraulicité (1982, 1989, 1990, 1991), mais il n'est pas limitant dans ce secteur de fleuve (minimum $=0,4 \mathrm{mg}^{-1}{ }^{-1}$ ). Une tendance à la diminution des nitrates à l'aval immédiat du rejet est à noter (seuil de significativité, $p=0,001$, tab. I), en parallèle avec l'augmentation du $\mathrm{pH}$. Les apports de nitrates se font non seulement par les rejets domestiques, mais aussi par le lessivage des sols, les quantités sont donc également liées aux débits, l'apport érosif étant moins important en période estivale. C'est durant les années 1980, 1981, 1987 et 1988, à forte hydraulicité, que les valeurs les plus fortes sont observées.

Les phosphates $\left(\mathrm{PO}_{4}^{3-}\right)$ sont soumis aux mêmes phénomènes d'apports et de consommation que les nitrates (minimum $=0,02 \mathrm{mg} . \mathrm{l}^{-1}$, maximum $=0,60 \mathrm{mg}^{-1} \mathrm{I}^{-1}$. Les valeurs moyennes qui sont successivement de $0,18{\mathrm{mg} . \mathrm{l}^{-1}}^{-1}$ en amont, de $0,16 \mathrm{mg}^{-\mathrm{l}^{-1}}$ et de $0,14 \mathrm{mg} . \mathrm{l}^{-1}$ en aval, indiquent une tendance à la consommation plus marquée à la station située plus en aval (fig. 7). Les moyennes mobiles confirment cette tendance, ainsi que le test non paramétrique $(p<0,001$, tab. 1$)$.

Les eaux sont naturellement riches en silice (minimum $=0,50 \mathrm{mg} \cdot \mathrm{l}^{-1}$, maximum $=15,5{\mathrm{mg} . l^{-1}}^{-1}$, en raison de la nature des terrains traversés et du lessivage des sols. La silice favorise le développement des Bacillariophycées, abondantes en périodes printanière et automnale. Les valeurs observées d'amont en aval sont proches les unes des autres, avec des moyennes de $6,7 \mathrm{mg.l}^{-1}$ $6,7{\mathrm{mg} . \mathrm{l}^{-1}}^{\text {et }} 6,9 \mathrm{mg} . \mathrm{l}^{-1}$; les moyennes mobiles révèlent une tendance à l'augmentation de ce paramètre à la station située le plus en aval (fig. 7), en particulier à partir de 1984 $(p<0,001$, tab. l). La consommation de cet élément est plus forte durant les années à faible hydraulicité.

\subsubsection{1 Éléments minéraux}

Sulfates $\left(\mathrm{SO}_{4}^{2-}\right)$, Calcium $\left(\mathrm{Ca}^{+}\right)$, Magnésium $\left(\mathrm{Mg}^{2-}\right)$, Titre Alcalimétrie Complet $\left(\mathrm{HCO}_{3}^{-}\right)$, Chlorures $\left(\mathrm{Cl}^{-}\right)$, Sodium $\left(\mathrm{Na}^{+}\right)$et Potassium $\left(\mathrm{K}^{+}\right)$contribuent à la minéralisation de l'eau. Les variations de l'ensemble de ces paramètres (tab. II) sont fortement liées à l'hydraulicité (lessivage des sols des régions traversées par la Loire), aux rejets domestiques déversés par les agglomérations situées en amont. Ils témoignent d'un milieu de productivité moyenne seIon la classification de Nisbet \& Vernaux (1970), sans lien avec le fonctionnement de la centrale.

\subsubsection{Une partie de fleuve productive}

Dans cette partie moyenne de la Loire, la vitesse du courant n'est plus un obstacle au développement d'une importante communauté planctonique, rejoignant en cela la typologie de Vannote et al. (1980) qui situe le déve- 
Tableau II. - Teneurs en éléments minéraux.

Table II. - Content in mineral components.

\begin{tabular}{|c|c|c|c|c|c|c|c|c|}
\hline & $\begin{array}{r}\mathrm{Ca} \\
\mathrm{mg} \cdot 1-1 \\
\end{array}$ & $\begin{array}{r}\mathrm{Mg} \\
\mathrm{mg} .1-1 \\
\end{array}$ & $\begin{array}{r}a \\
m g .1 \cdot 1 \\
\end{array}$ & $\begin{array}{l}\mathrm{SO}_{4} \\
\mathrm{mp} .1-1\end{array}$ & $\begin{array}{r}\mathrm{Na} \\
\mathrm{mg} \cdot 1-1\end{array}$ & $\begin{array}{r}\mathrm{K} \\
\mathrm{mg} \cdot 1-1 \\
\end{array}$ & $\begin{array}{r}\text { T.A.C. } \\
\text { m..111 }\end{array}$ & $\begin{array}{r}\text { T.A. } \\
\text { mg.l-1 }\end{array}$ \\
\hline 31 Minimum & 19,0 & 3,1 & 6.0 & 12.8 & 6.4 & 2.7 & 56.4 & 0. \\
\hline Maximum & 50.7 & 6,9 & 22.5 & 34,0 & 25.2 & 5,0 & 163,0 & 34,0 \\
\hline Moyenne & 31,9 & 5,0 & 13.9 & 21.4 & 13,1 & 3,8 & 103.9 & 10,6 \\
\hline Ecart type & 6.7 & 0,8 & 3,3 & 3,9 & 3.4 & 0.5 & 19.7 & 7. \\
\hline Coef. de var. & $21 \%$ & $16 \%$ & $24 \%$ & $18 \%$ & $26 \%$ & $13 \%$ & $19 \%$ & $73 \%$ \\
\hline 32a Minimum & 19.0 & 3,0 & 5,0 & 12,6 & 6.4 & 2,6 & 45,0 & 0 \\
\hline Maximum & 48,5 & 7,5 & 22.0 & 32.5 & 25,8 & 5.3 & 158,0 & 37,0 \\
\hline Moyenne & 31,6 & 5,1 & 13,8 & 21,2 & 13,1 & 3,8 & 102,3 & 10, \\
\hline Ecart type & 6,0 & 0,8 & 3.3 & 3,6 & 3,5 & 0.5 & 19.0 & 7.5 \\
\hline Coef. de var. & $19 \%$ & $16 \%$ & $24 \%$ & $17 \%$ & $26 \%$ & $14 \%$ & $19 \%$ & $71 \%$ \\
\hline $32 b$ Minimum & 20.0 & 3,0 & 6.0 & 12.8 & 1,0 & 2,6 & 58,0 & 0, \\
\hline Maximum & 47,5 & 7,5 & 24.2 & 31.5 & 25.8 & 5.2 & 149.0 & 37.0 \\
\hline Moyenno & 31,9 & 5,0 & 14,0 & 21,2 & 13,1 & 3.8 & 103,5 & 11,0 \\
\hline Ecart type & 5.8 & 0.8 & 3.5 & 3.6 & 3.7 & 0.5 & 17.4 & 8.5 \\
\hline Coel. de var. & $18 \%$ & $16 \%$ & $25 \%$ & $17 \%$ & $28 \%$ & $14 \%$ & $17 \%$ & $78 \%$ \\
\hline
\end{tabular}

loppement phytoplanctonique à un niveau d'ordre $>6$ dans la taille des cours d'eau. Le cercle de corrélations extrait de l'analyse en composantes principales sur la période 1982-1994 (104 séries d'observations réalisées sur 13 ans), illustre parfaitement l'influence de l'activité photosynthétique: $\mathrm{PO}_{4}, \mathrm{NO}_{3}$ et $\mathrm{SiO}_{2}$, consommés en période de croissance algale, sont opposés à $\mathrm{DBO}_{5}, \mathrm{pH}$ et $\mathrm{O}_{2}$ auxquels est associée la biomasse algale (fig. 8) ; les débits, opposés à pH, $\mathrm{O}_{2}$, $\mathrm{DBO}_{5}$ et $\mathrm{t}^{\circ} \mathrm{C}$, illustrent l'importance du régime hydraulique et confirment nos observations précédentes (Lair \& Sargos, 1993).

\subsection{Suivi écologique des microal- gues planctoniques et benthiques}

Nous avons procédé à un examen systématique et quantitatif des commu- nautés végétales planctoniques, de manière à en connaître la structure et à déterminer les populations susceptibles de coloniser les fonds ou de s'en détacher. Puis nous avons étudié les communautés benthiques (périlithon) de manière à comparer leur structure amont/aval au moyen de différents indices.

\subsubsection{Richesse taxonomique du phy- toplancton}

Les données sont disponibles à partir de 1982 seulement.

La richesse taxonomique varie d'une année à l'autre, elle est maximale lors de l'étiage estival et le nombre moyen de taxons oscille autour de 31 (fig. 9). Au total, 160 taxons (espèces et variétés) appartenant à 8 classes ont été inventoriés au cours de ces années d'étude (tab. III). Leur répartition montre la dominance, en 


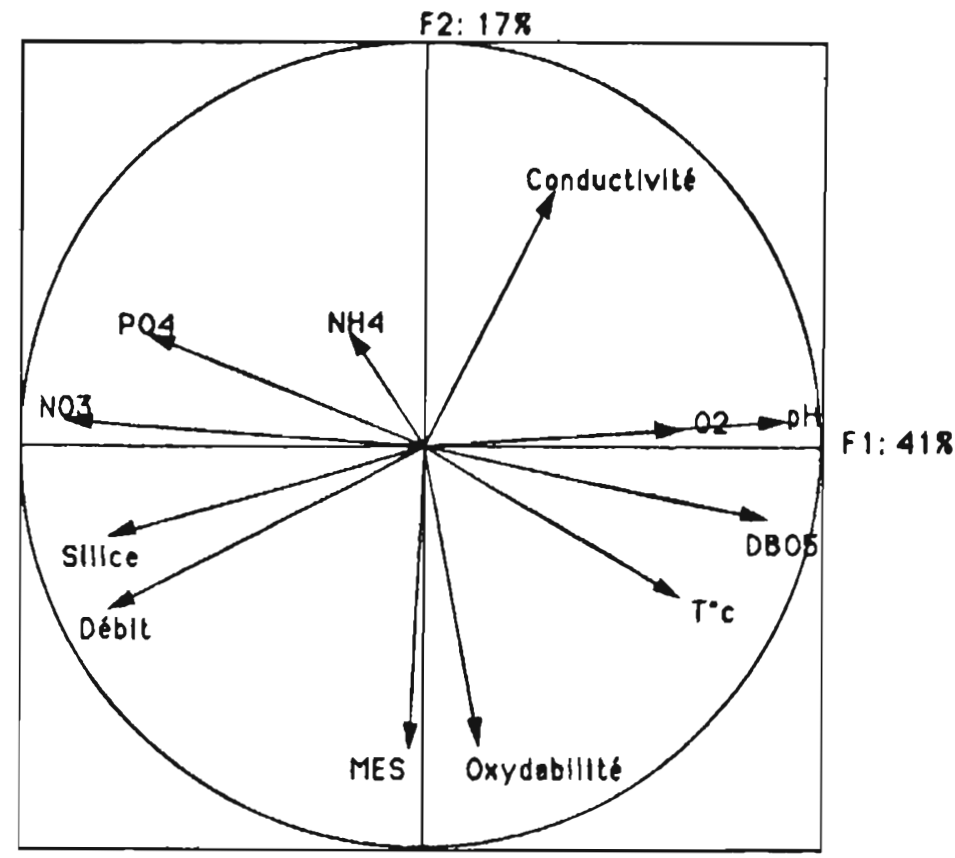

Fig. 8. - Distribution des variables abiotiques dans le cercle de corrélations du plan F1 x F2 de l'Analyse en Composantes Principales normée.

Fig. 8. - Situation of the measured abiotic variables in the plane of axis I and II, resulting from PCA.

Tableau III. - Bilan taxonomique de la microflore planctonique.

Table III. - Taxonomy of the planktonic microflora.

\begin{tabular}{|llr|}
\hline Schizophyta & Cyanooacteria & 18 \\
Euglenophyta & Euglenophyceae & 2 \\
Chlorophyta & Chlorophyceae & 109 \\
& Zygophyceae & 4 \\
Chromophyta & Chrysophyceae & 2 \\
& Baciliariophyceae & 22 \\
Pyrrhophyta & Cryptophyceae & 2 \\
& Dinophyceae & 1 \\
\hline Nombre total de taxons & 160 \\
\hline
\end{tabular}

terme de richesse taxonomique, des Chlorococcales, suivie par les Bacillariophycées. Le nombre relativement restreint de Cyanobactéries obser- vées indique que ce groupe d'algues ne fait pas partie des composants habituels de la flore planctonique ligérienne. II n'y a pas de différence significative entre les stations.

Le groupe des Chlorophycées est le plus diversifié en période estivale. Les Volvocales sont représentées par des formes coloniales (Pandorina sp., Eudorina sp.) et solitaires (Chlamydomonas sp.). Les Chlorococcales les plus fréquentes sont des formes cœnobiales (Cœlastrum spp., Scenedesmus spp., Pediastrum spp. et Dictyosphaerium spp.), ce sont également les algues dominantes du plancton es- 
Richesse specifique

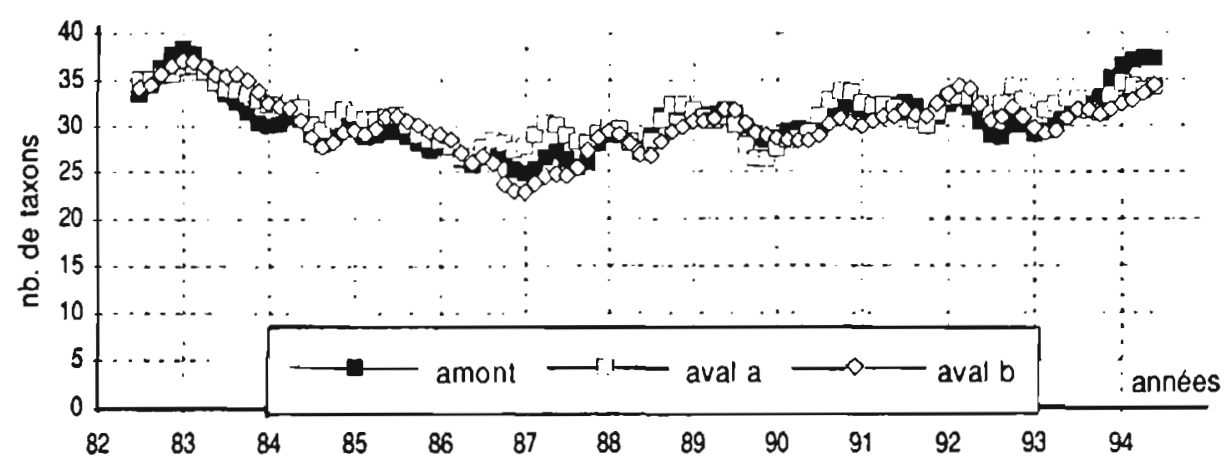

Densité cellulaire

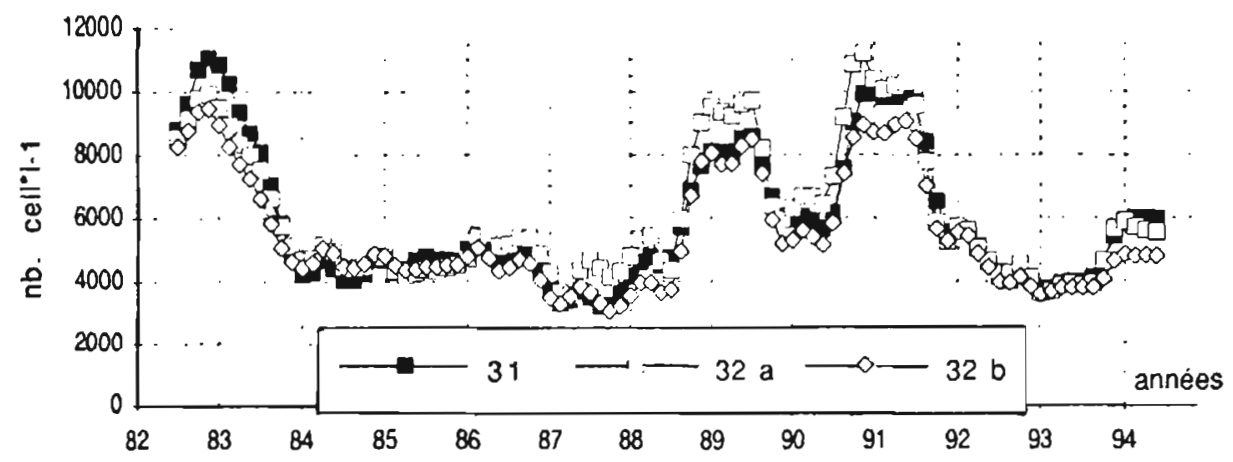

Biomasse algale

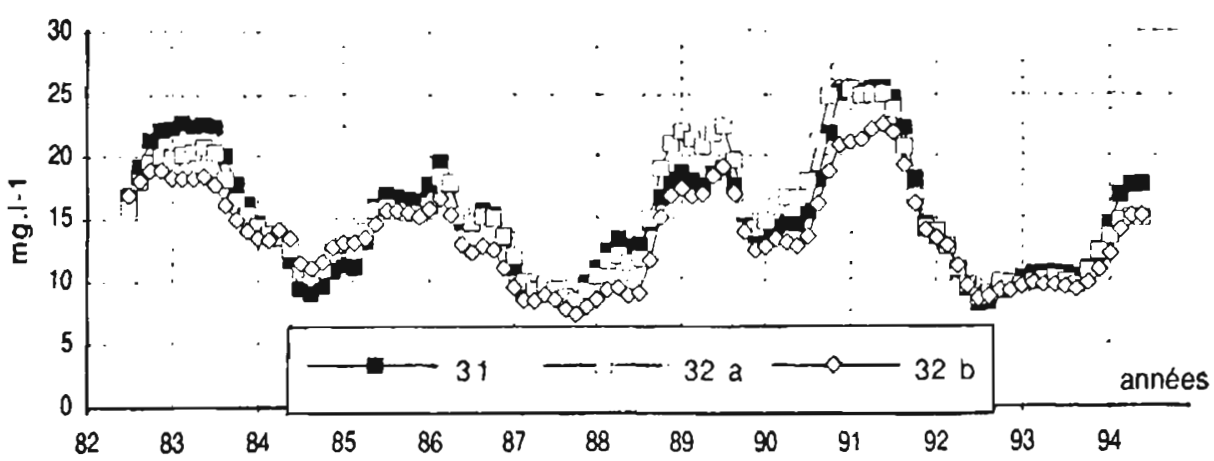

Fig. 9. - Variations de la richesse spécifique, de la densité et de la biomasse du phytoplancton (moyennes mobiles) aux stations amont $\left(3_{1}\right)$, aval immédiat $\left(3_{2} a\right)$ et aval éloigné $\left(3_{2} b\right)$.

Fig. 9. - Variations in phytoplankton species richness, density and biomass (moving averages), measured upstream $\left(3_{1}\right)$, immediately after the power plant $\left(3_{2} a\right)$ and more downstream $\left(3_{2} b\right)$. 
tival. Les Zygnématales sont assez rares, Staurastrum paradoxum est l'espèce la plus fréquente et celles appartenant à ce groupe sont généralement benthiques (Closterium spp.).

Les Bacillariophycées planctoniques vraies sont peu nombreuses par rapport aux espèces benthiques et tychoplanctoniques. Les diatomées centriques les plus fréquentes et les plus abondantes dans le plancton de ce fleuve appartiennent aux genres Cyclotella, Stephanodiscus et Melosira et les diatomées pennées sont dominées par les genres Asterionella, Nitzschia, Navicula et Fragilaria.

Les deux genres de Chrysophycées, qui se développent généralement en hiver, sont rarement observés dans les échantillons, en raison de leur fragilité, et surtout de la période étudiée. Les Euglénophycées sont représentées par 3 genres (Euglena, Phacus, Trachelomonas). Parmi les Pyrrophytes, en période estivale la classe des Dinophycées n'est représentée que par le genre Peridinium dont la présence est occasionnelle. Par contre, les Cryptophycées ont plusieurs représentants du genre Cryptomonas dont le développement peut être important. Les Cyanobactéries se développent de manière ponctuelle en periode de basses eaux, sans que l'on puisse parler véritablement de fleurs d'eau, à l'exception du mois d'août 1994.

\subsubsection{Densité et biomasse phyto- planctonique}

Globalement la densité algale varie

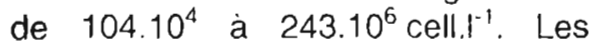
moyennes mobiles permettent de met- tre en évidence de larges fluctuations en relation avec les variations du régime hydraulique (fig. 9), avec de fortes densités durant les années de sécheresse (1982, 1989 à 1991). Une augmentation de densité se produit à l'aval du rejet, significative à la station la plus éloignée $(p<0,05$, tab. IV). La courbe des biomasses indique la même tendance (fig. 9), avec une différence significative à $p<0,001$ (tab. IV).

D'un point de vue générique, le genre Cyclotella comprend une bonne proportion d'espèces de grande taille jusqu'en 1986. A partir de cette année là, des taxons proportionnellement de plus petite taille, ainsi que des genres dont les espèces sont classées dans la gamme de qualité d'eaux $\beta$ mésosaprobes deviennent plus abondants, à savoir : Actinastrum, Dictyosphaerium, Pediastrum, Scenedesmus, Nitzschia.

La diversité spécifique varie très peu d'une station à l'autre (fig. 10). A deux exceptions près (en 1990 et 1994 les valeurs brutes sont descendues à 1,73 bits.cell $^{-1}$ et à 1,77 bits.cell $^{-1}$ respectivement), quelles que soient les stations, les valeurs ne descendent pas au dessous de 2,5 bits.cell ${ }^{-1}$. La moyenne proche de 4 , témoigne de peuplements bien structurés. II n'y a pas de différences significatives entre les secteurs, illustrant l'absence d'influence des rejets de la centrale sur la structure d'ensemble des peuplements.

Le développement des Chlorophycées est plus accentué en aval de 1986 à 1990 mais sur l'ensemble des données la différence n'est pas significative (fig. 10, tab. IV). A l'inverse, la 
Tableau IV. - Valeurs minimale, moyenne et maximale des données phytoplancton. Résultats du test de Wilcoxon des valeurs appariées.

Table IV. - Minima, mean and maxima values of the different phytoplankton variables and Wilcoxon test (paired data).

\begin{tabular}{|c|c|c|c|c|c|}
\hline \multicolumn{2}{|c|}{ PHYTOPLANCTON } & $\begin{array}{l}\text { Richesse } \\
\text { nb. de taxons }\end{array}$ & $\begin{array}{r}\text { Densité } \\
10^{4} . \text { cell. } 1^{-1}\end{array}$ & $\begin{array}{c}\text { Biomasse } \\
\text { mg.l }\end{array}$ & $\begin{array}{l}\text { Diversité } \\
\text { Bit.cell }^{-1}\end{array}$ \\
\hline \multirow[t]{4}{*}{31} & minimum & 10 & 104 & 0,39 & 1.77 \\
\hline & maxımum & 55 & 18290 & 49,22 & 4,82 \\
\hline & moyenne & 31 & 6005 & 15.37 & 3.78 \\
\hline & écart type & 8 & 4140 & 10,19 & 0,57 \\
\hline \multirow[t]{4}{*}{32 a } & minimum & 9 & 114 & 0.43 & 1.73 \\
\hline & maximum & 55 & 24300 & 49,40 & 4,74 \\
\hline & moyenne & 31 & 6173 & 15,28 & 3.74 \\
\hline & écart type & 9 & 4551 & 10.12 & 0,60 \\
\hline \multirow[t]{4}{*}{$32 \mathrm{~b}$} & minimum & 0 & 154 & 0,64 & 1.87 \\
\hline & maximum & 47 & 18700 & 40.50 & 4.92 \\
\hline & moyenne & 31 & 5528 & 13.91 & 3.78 \\
\hline & écart type & 8 & 3715 & 8,77 & 0.59 \\
\hline
\end{tabular}

Test de Wilcoxon

$31-32$ a

$31-32 b$

32 a-32 o

Biomasse (mg.l')

31

minimum

maximum

moyenne

écant type

32 a

minimum

maximum

moyenne

écart type

$32 \mathrm{~b}$

minımum

maximum

moyenne

écart type

Cyanobactèries

ns

ns

ns

ns

$\rho<0.05$

$p<0.01$

$p<0.001$

$p<0.01$

Diălomées

Autres

0.00

0.18

5.17

0.15

32.96

15.05

0.35

1,51

7.12

6.08

0.00

0.16

20.20

0.39

24.71

6.53

2.01

5.15
0.13

30.25

8,72

6.13

0.16

25.36

8.56

5.86

0.11

28.04

7.53

5.69

0,00

1.18

0.25

0,30

0.00

1.70

0.28

0.36

0.00

1.64

0.25

0.28

\section{Test de Wilcoxon}

$31.32 a$
$31.32 b$
$32 a-32 b$




\section{Diversité spécifique}

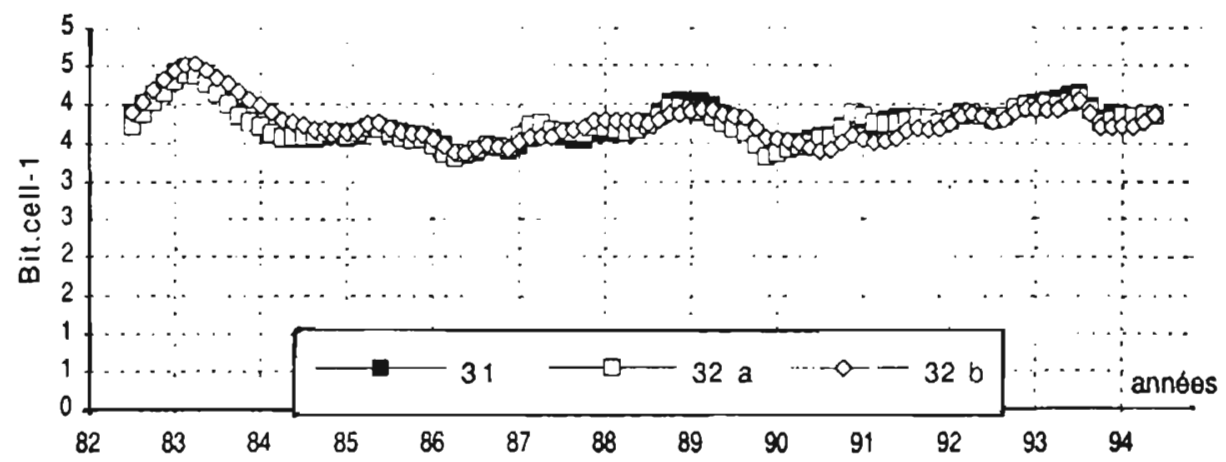

Chlorophycées

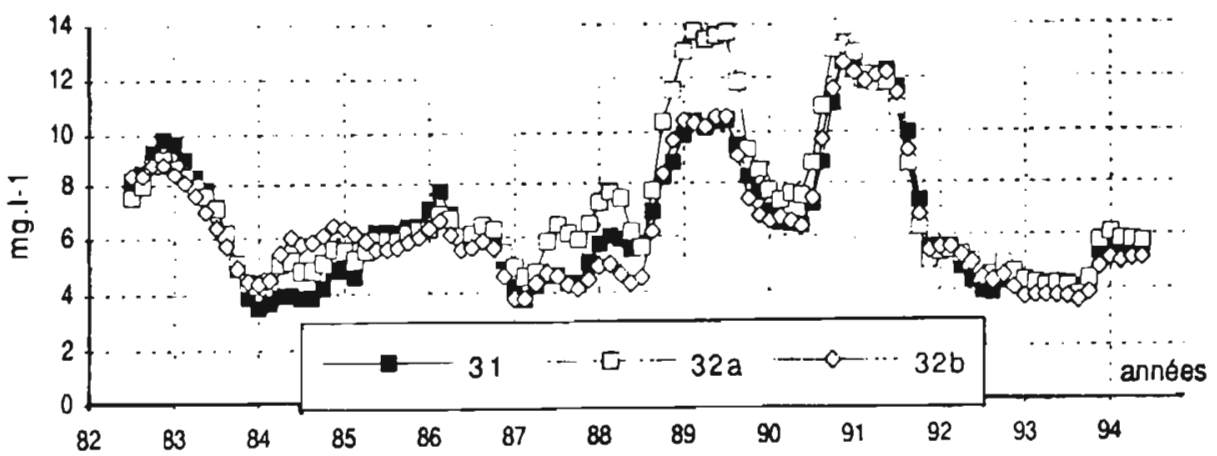

\section{Diatomées}

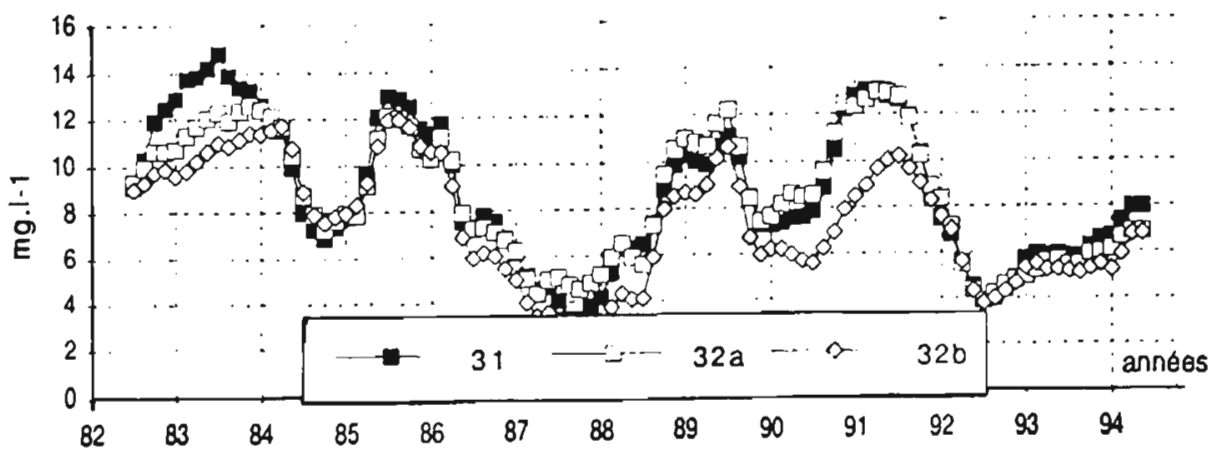

Fig. 10. - Variations de la diversité spécifique du phytoplancton et de la biomasse des Chlorophycees et des Bacillariophycées aux stations amont $\left(3_{1}\right)$, aval immédiat $\left(3_{2}\right.$ a) et aval éloigné $\left(3_{2} b\right)$. Fig. 10. - Variations in phytoplankton species diversity and in Chlorophyta and Bacillariophyta biomass measured upstream $\left(3_{1}\right)$, immediately after the power plant $\left(3_{2} a\right)$ and more downstream $\left(3_{2} b\right)$. 
diminution de biomasse des Bacillariophycées (fig. 10) est significative à la station la plus aval par rapport à l'amont ( $p<0,001$, tab. IV). Nous ne disposons pas des éléments permettant de juger des stratégies de croissance liées au développement de ces microalgues, d'autant que leurs potentialités d'accroissement sont non seulement spécifiques mais dépendent de l'état physiologique de chaque population. Les diatomées sont de bons compétiteurs vis à vis du phosphore et sont favorisées par une augmentation du rapport Si / $\mathrm{P}$ qu'elles font par ailleurs chuter (Sommer, 1988). Nous avons remarqué que la diminution de densité de ces algues en $3_{2 b}$ se produit parallèlement à l'augmentation amont - aval des rapports $\mathrm{NO}_{3} / \mathrm{PO}_{4}$ et $\mathrm{SiO}_{2} / \mathrm{PO}_{4}$, ce qui ne permet pas d'expliquer cette diminution; est-ce dû au broutage des consommateurs? Nous ne disposons pas des éléments pour en juger, seules des observations réalisées en 1995, suite à la reprise de l'étude des consommateurs planctoniques, montrent à certaines périodes une augmentation notable de densité des rotifères d'amont en aval (Lair \& Reyes-Marchant, 1997). II est certain que les processus sont complexes.

Que ce soit en densité (fig. 11), ou en biomasse (fig. 12), les Chlorophycées et les Bacillariophycées sont les groupes les mieux représentés. Les Cyanobactéries, dont la densité représente seulement 2 à $3 \%$ par rapport aux autres groupes, se développent durant les périodes de sécheresse; le phénomène est particulièrement net en 1982, 1989, 1990 et 1991; elles se sont également développées en 1983 et 1992 à la faveur d'un faible débit estival et d'une chute des teneurs en nitrates, ainsi qu'en 1994 où leur développement s'est avéré particulièrement important (fig. 12).

\subsubsection{Algues périphytiques}

Ce sont les Bacillariophycées qui ont servi de base à cette étude.

La richesse taxonomique (espèces et variétés) des diatomées déposées sur les substrats naturels oscille entre 16 et 41 taxons, avec des moyennes de 30 à 31 selon les stations (fig. 13). La diversité spécifique maximum atteint 4,80 bits.cell- ${ }^{1} \quad$ (minimum $=$ 2,41 bits.cell $^{-1}$ ); le peuplement de diatomées épilithiques demeure bien structuré, comme en témoigne la courbe des moyennes mobiles (fig. 13) et il n'y a pas de différence significative entre les stations (tab. V).

L'indice de polluosensibilité (IPS) révèle dans l'ensemble une eau de meilleure qualité en amont par rapport aux stations aval, en particulier à partir de 1986 (fig 14); la différence entre amont et aval immédiat du rejet est significative à $p<0,01$ (tab. V). Ceci est confirmé par les valeurs de l'indice CEC qui, à partir de 1986, sont le plus souvent inférieures en aval, témoignant d'une légère dégradation de la qualité des eaux après la centrale, excepté en 1992 (fig. 14); la différence entre la station amont et les 2 stations aval est significative à $\mathrm{p}<0,05$ (tab. IV).

Aucun support artificiel n'a été placé à l'aval immédiat du rejet, nous dis- 

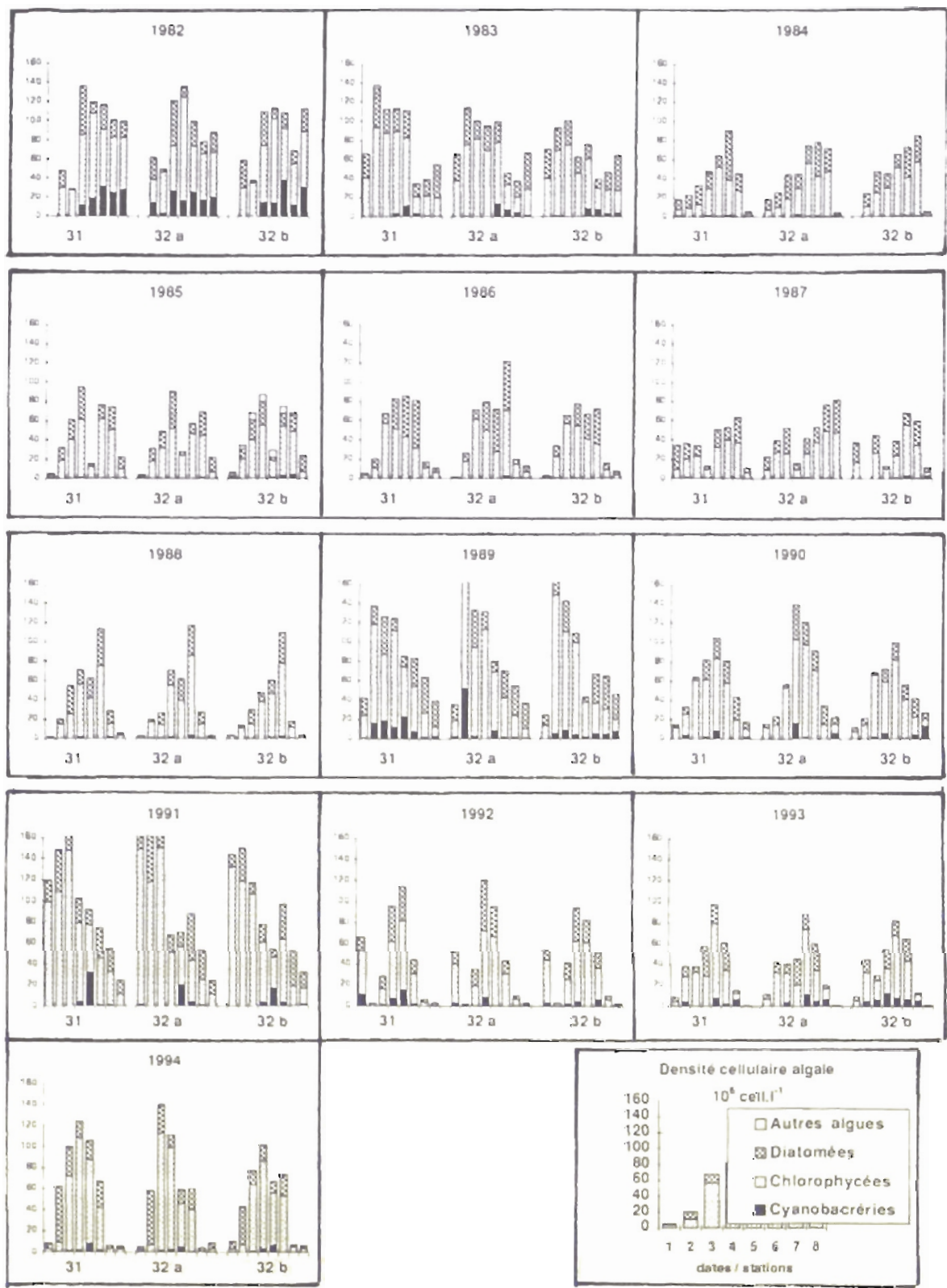

Fig. 11. - Variation de la densité des principaux groupes composant le phytoplancton aux stations amont $\left(3_{1}\right)$, aval immédiat $\left(3_{2} \mathrm{a}\right)$ et aval éloigné $\left(3_{2} \mathrm{~b}\right)$.

Fig. 11. - Variations in density of the principal phytoplankton components measured upstream $\left(3_{1}\right)$, immediately after the power plant $\left(3_{2} a\right)$ and more downstream $\left(3_{2} b\right)$. 

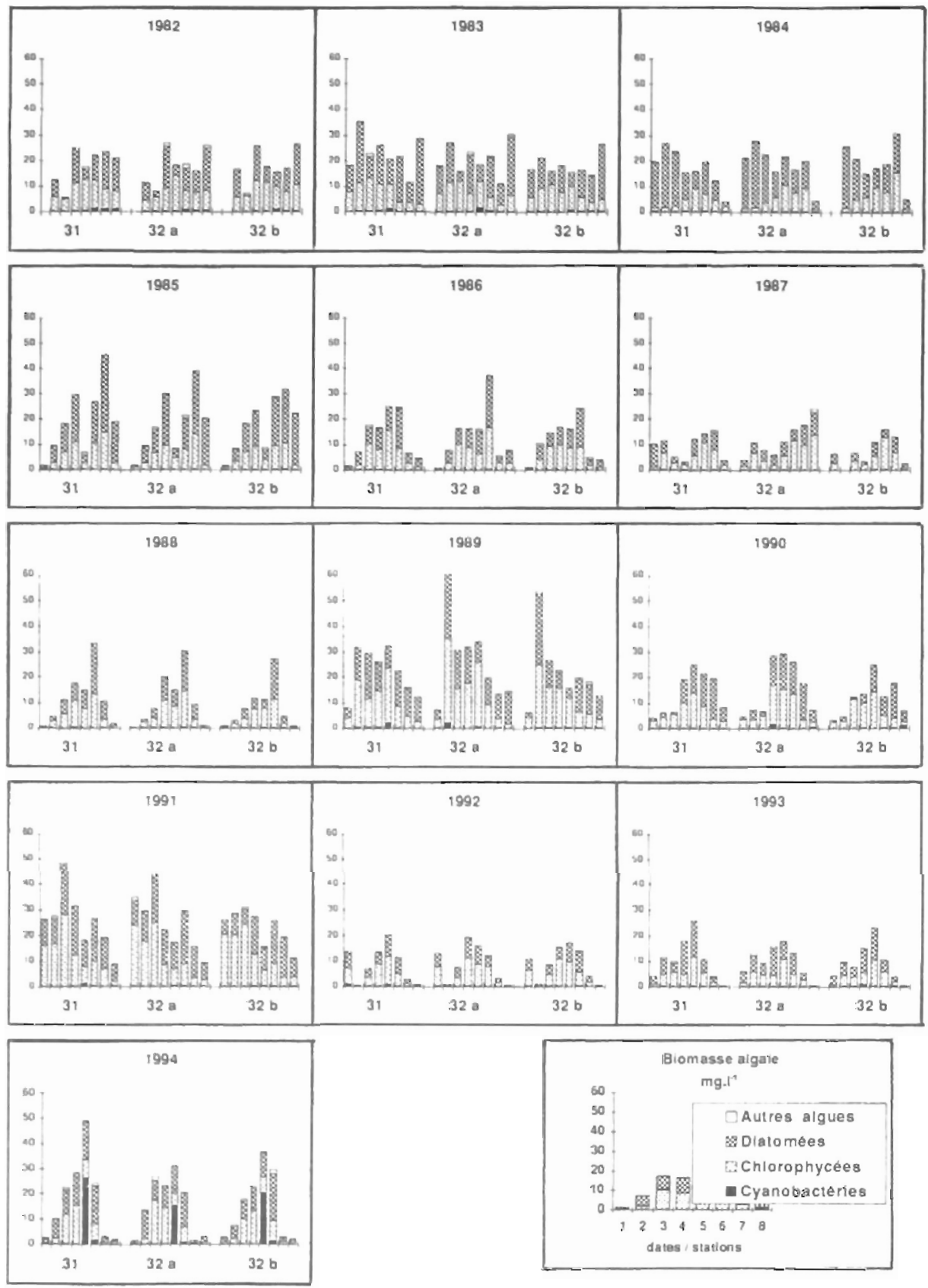

Fig. 12. - Variation de la biomasse des principaux groupes composant le phytoplancton aux stations amont $\left(3_{1}\right)$, aval immédiat $\left(3_{2} \mathrm{a}\right)$ et aval éloigné $\left(3_{2} \mathrm{~b}\right)$.

Fig. 12. - Variations in biomass of the principal phytoplankton components measured upstream $\left(3_{1}\right)$, immediately after the power plant $\left(3_{2} a\right)$ and more downstream $\left(3_{2} b\right)$. 


\section{Rlchesse taxonomique}

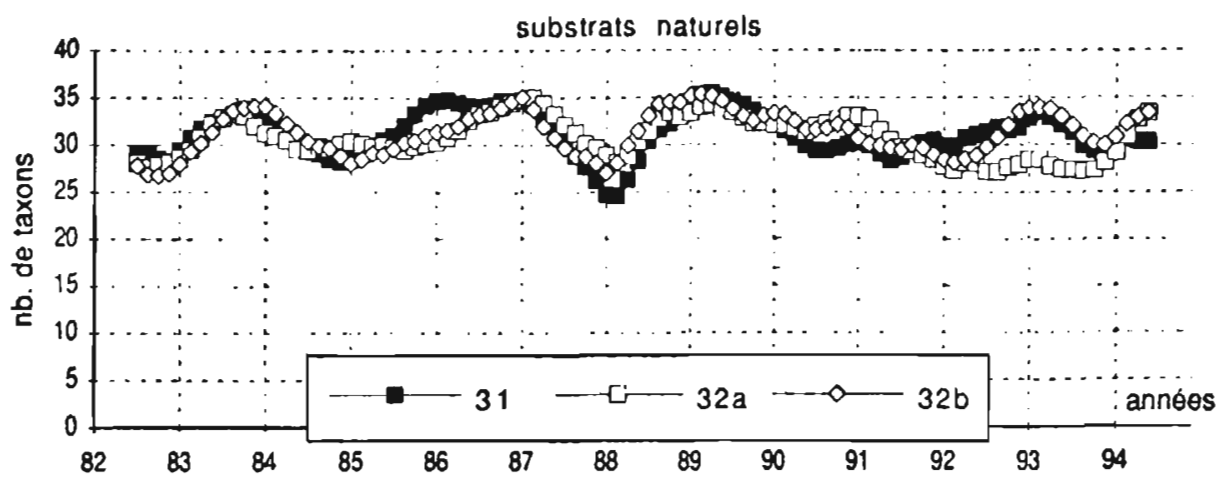

\section{Diversité}

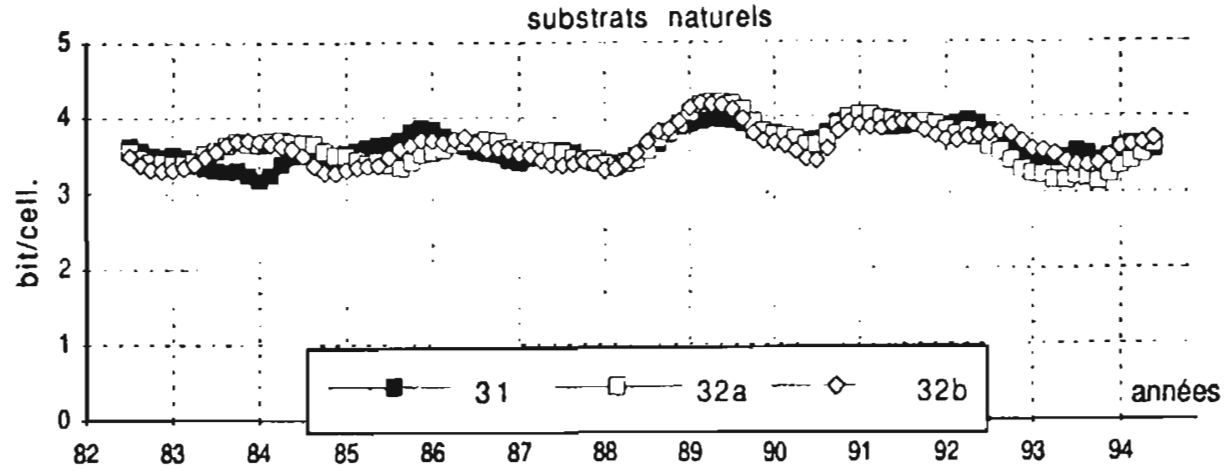

Fig. 13. - Variations de la richesse taxonomique et de la diversité taxonomique (espèces et variétés) des Bacillariophycées périlithiques (moyennes mobiles) collectées sur substrats naturels aux stations amont $\left(3_{1}\right)$, aval immédiat $\left(3_{2} a\right)$ et aval éloigné $\left(3_{2} b\right)$.

Fig. 13. - Variation in taxonomix richness and diversity of epilithic diatoms, deposed on natural substratum, measured upstream $\left(3_{1}\right)$, immediately after the power plant $\left(3_{2} a\right)$ and more downstream $\left(3_{2} b\right)$.

posons des données amont (où ces supports sont déposés à l'entrée du canal d'amenée, dont les conditions hydrauliques sont relativement stables) et des données du secteur situé à plusieurs kilomètres en aval (où les supports artificiels déposés non loin du bord, sont soumis aux variations du niveau de l'eau).
Sur les supports artificiels, pour lesquels un temps de colonisation de 2 semaines en période estivale s'est avéré globalement satisfaisant, la richesse spécifique varie de 14 à 53 , avec des moyennes de 29 à 30 (fig. 15). De 1987 à 1994 (excepté en 1992, année relativement atypique à l'égard de nombreux parametres), sur 
Tableau V. - Valeurs minimale, moyenne et maximale des données périphyton. Résultats du test de Wilcoxon des valeurs appariées.

Table V. - Minima, mean and maxima values of the different components of the epilithic populations and Wilcoxon test (paired data).

\begin{tabular}{|c|c|c|c|c|c|c|}
\hline \multirow{2}{*}{\multicolumn{2}{|c|}{$\begin{array}{l}\text { Périphyton } \\
\text { Supports artificlels }\end{array}$}} & Richesse & Densité & \multirow{2}{*}{$\begin{array}{l}\text { Diversité } \\
\text { Bit.cell }^{-1}\end{array}$} & \multirow[t]{2}{*}{ PS } & \multirow[t]{2}{*}{ CEC } \\
\hline & & \multicolumn{2}{|c|}{$10^{4}$. cell. $\mathrm{cm}^{2}$} & & & \\
\hline \multirow[t]{4}{*}{31} & minimum & 14 & 2.5 & 0,97 & 3,87 & 1 \\
\hline & maximum & 49 & 725 & 4,74 & 16,23 & 18.1 \\
\hline & moyenne & 30.0 & 102.2 & 3,24 & 9.71 & 8,8 \\
\hline & écart type & 6.5 & 109.4 & 0.79 & 2,32 & 3,8 \\
\hline \multirow[t]{4}{*}{$32 \mathrm{~b}$} & minimum & 14 & 1.7 & 1,21 & 4.13 & 1 \\
\hline & maximum & 53 & 762 & 5.08 & 14.51 & 18.1 \\
\hline & moyenne & 29.1 & 92,0 & 3.18 & 9.49 & 9.2 \\
\hline & écart type & 6,9 & 102.3 & 0.73 & 2,30 & 4.1 \\
\hline \multicolumn{2}{|c|}{ Test de Wilcoxon } & $S$ & & & & \\
\hline & $31-32 b$ & ns & ns & ns & ns & ns \\
\hline \multicolumn{2}{|c|}{ Periphyton } & Richesse & & Diversité & $\mathbf{P S}$ & CEC \\
\hline \multicolumn{7}{|c|}{ Substrats naturels } \\
\hline \multirow[t]{4}{*}{31} & minimum & 16 & & 2.3 & 6.9 & 2.9 \\
\hline & maximum & 50 & & 4.6 & 14.8 & 18,1 \\
\hline & moyenne & 30.9 & & 3.6 & 11.2 & 12.0 \\
\hline & écart type & 6.14 & & 0.48 & 1,94 & 3,96 \\
\hline \multirow[t]{4}{*}{$32 \mathrm{a}$} & minimum & 18 & & 2.1 & 7,4 & 4.8 \\
\hline & maximum & 45 & & 4,7 & 14,2 & 18.1 \\
\hline & moyenne & 30.7 & & 3.6 & 10.8 & 11.1 \\
\hline & écart type & 5.59 & & 0,58 & 1,62 & 3.53 \\
\hline \multirow[t]{4}{*}{$32 \mathrm{~b}$} & minımum & 17 & & 2.3 & 7,6 & 4.8 \\
\hline & maxımum & 46 & & 4,8 & 14,8 & 18,1 \\
\hline & moyenne & 31.1 & & 3.6 & 10.9 & 11.4 \\
\hline & écart type & 5.58 & & 0.54 & 1.82 & 3,78 \\
\hline \multicolumn{7}{|c|}{ Test de Wilcoxon } \\
\hline & 31.32 a & ns & & ns & $p<0.01$ & $p<0.05$ \\
\hline & $31-32 b$ & ns & & ns & ns & $p<0,05$ \\
\hline & $32 \mathrm{a}-32 \mathrm{~b}$ & ns & & ns & ns & ns \\
\hline
\end{tabular}




\section{IPS}

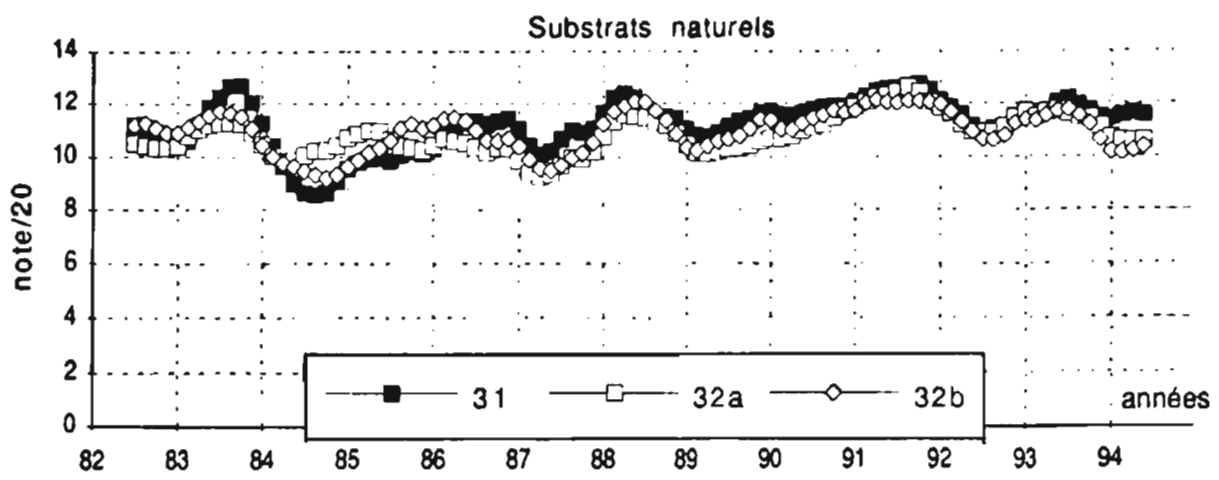

\section{CEC}

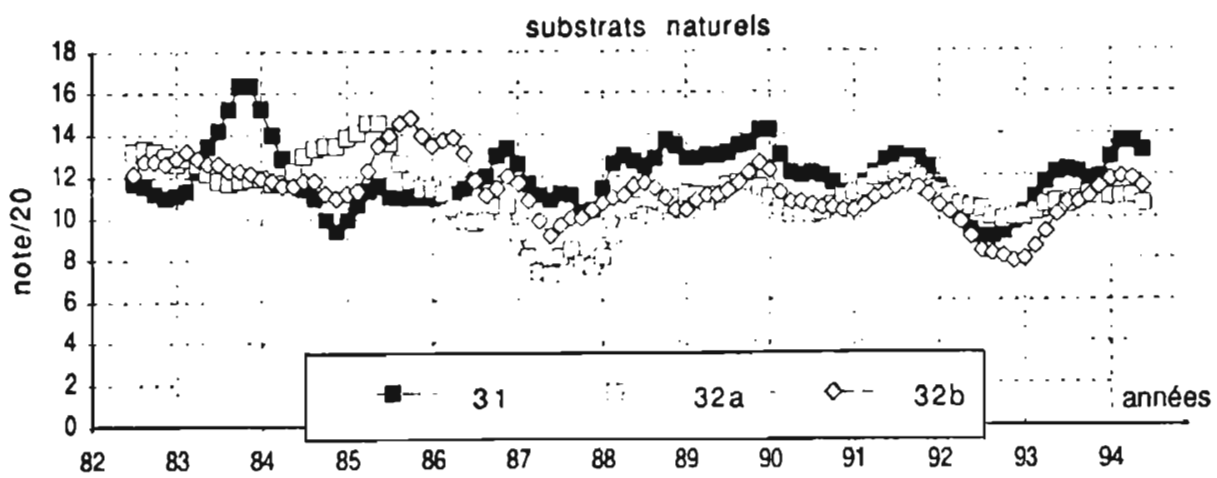

Fig. 14. - Variations des indices diatomiques IPS ef CEC des Bacillariophycées périlithiques (moyennes mobiles) collectées sur substrats naturels aux stations amont $\left(3_{1}\right)$, aval immédiat $\left(3_{2} a\right)$ et aval éloigné $\left(3_{2} b\right)$.

Fig. 14. - Variations in IPS and CEC diatom index (moving averages), measured upstream $\left(3_{1}\right)$, immediately after the power plant $\left(3_{2} a\right)$ and more downstream $\left(3_{2} b\right)$ from natural substratum.

les supports artificiels la richesse spécifique est plus forte à la station amont. Cependant, sur l'ensemble des observations, la différence n'est pas significative.

La densité des algues qui colonisent ces supports artificiels varie de $1,7.10^{4}$ a $762.10^{4}$ cell.cm ${ }^{2}$; sur l'en- semble des données, la différence entre amont et aval n'est pas significative (tab. V). Par contre, au regard des moyennes mobiles (fig. 15), les algues périphytiques paraissent nettement plus denses dans le secteur amont à partir de 1989 (exception faite de l'année 1992) et la différence 

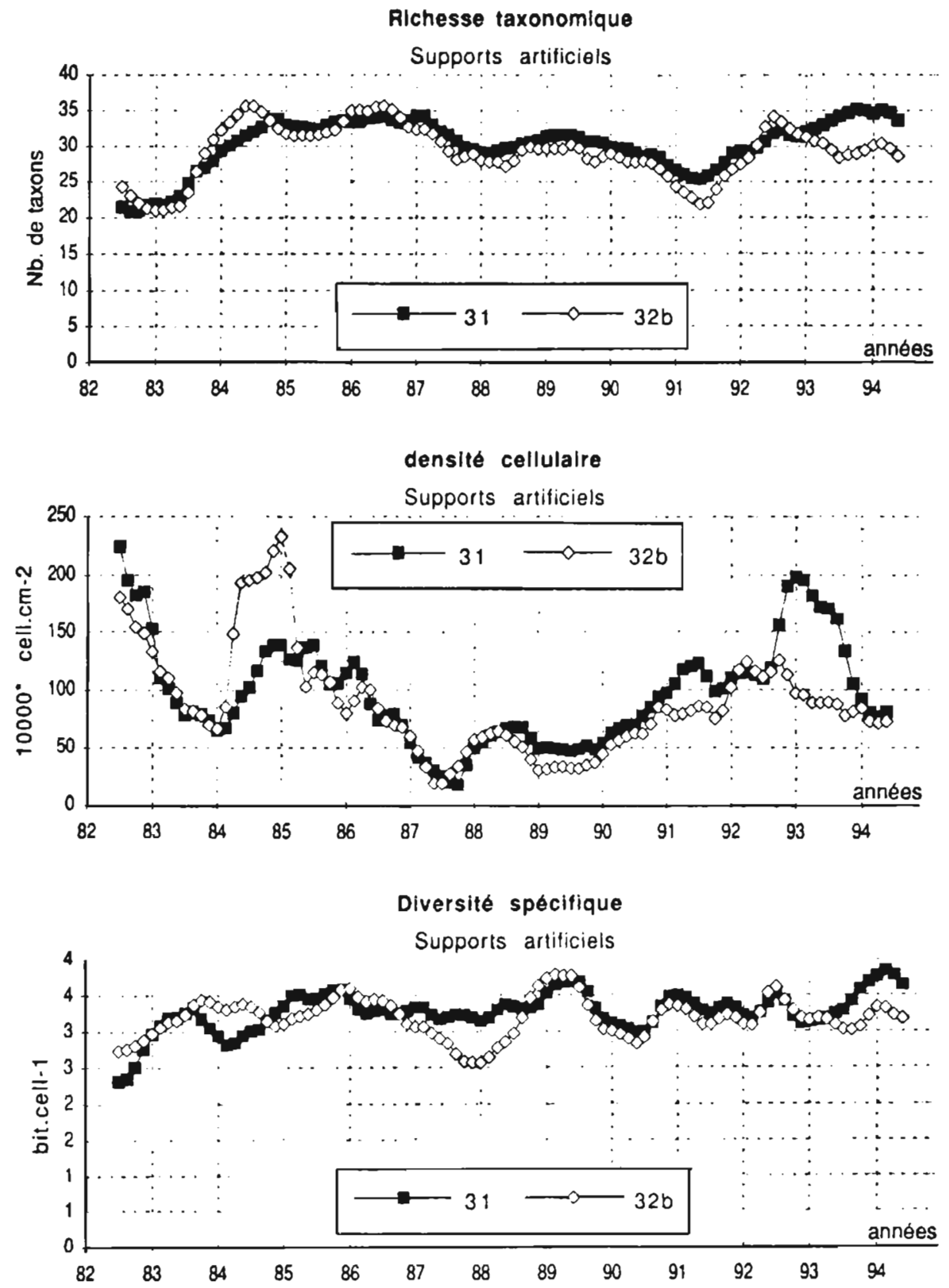

Fig. 15. - Variations de la richesse taxonomique, de la densité et de la diversité spécifique des Bacillariophycées périlithiques déposées sur supports artificiels (moyennes mobiles) aux stations amont $\left(3_{1}\right)$ et aval éloigné $\left(3_{2} b\right)$.

Fig. 15. - Variations in taxonomic richness and diversity of diatoms, deposed on artificial substratum (moving averages), measured upstream $\left(3_{1}\right)$, immediately after the power plant $\left(3_{2} a\right)$ and more downstream $\left(3_{2} b\right)$. 

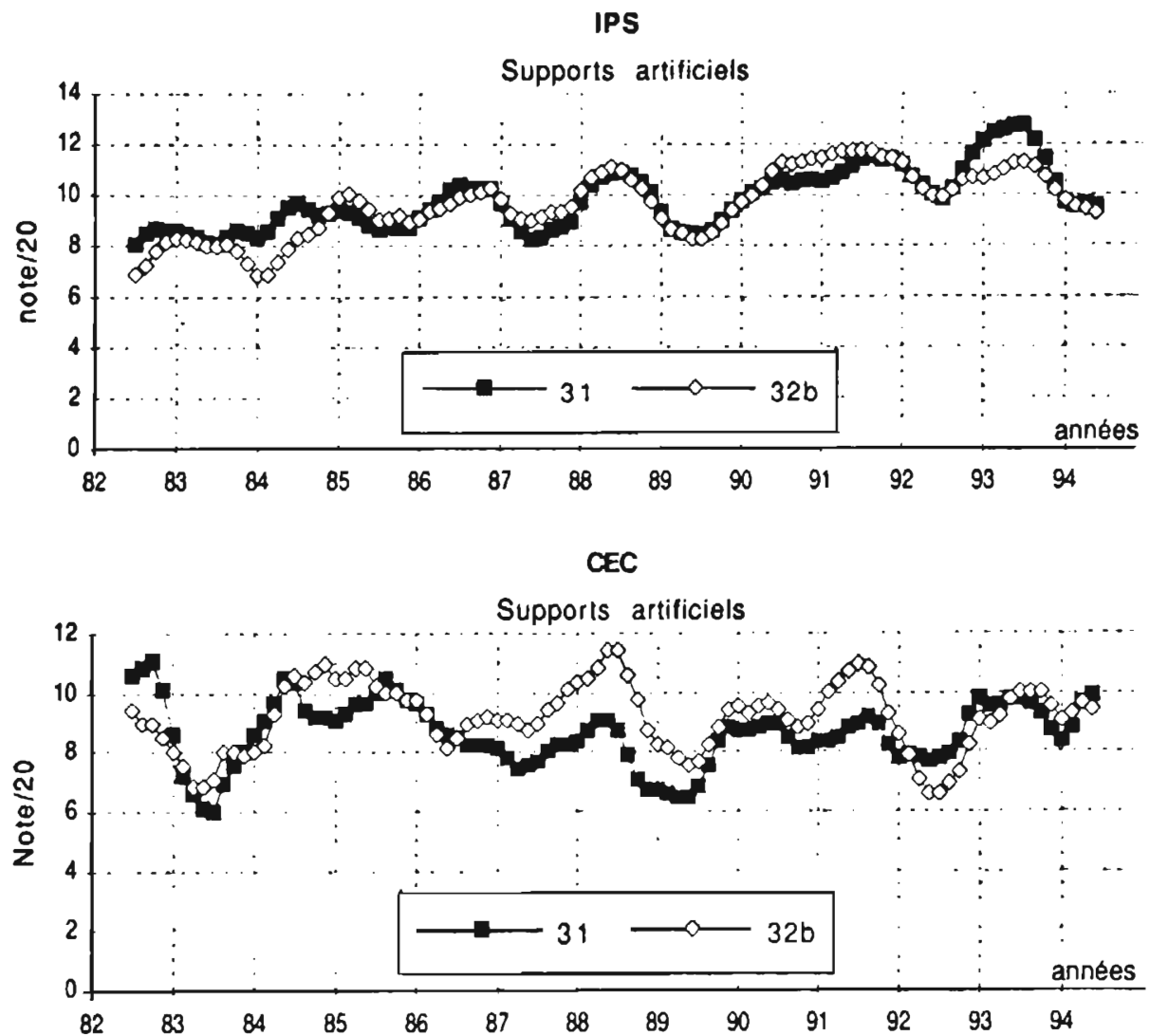

Fig. 16. - Variations des indices diatomiques IPS et CEC des Bacillariophycées périlithiques (moyennes mobiles) collectees sur supports artificiels aux stations amont $\left(3_{1}\right)$ et aval éloigné $\left(3_{2} b\right)$. Fig. 16. - Variations in IPS and CEC diatom index (moving averages), measured upstream $\left(3_{1}\right)$, immediately after the power plant $\left(3_{2} a\right)$ and more downstream $\left(3_{2} b\right)$ from artificial substratum.

de densité entre amont et aval est significative durant cette période d'étude $(p<0,05$, tab. $V)$.

L'amplitude des variations de la diversité spécifique des diatomées colonisatrices des supports artificiels est plus grande que celle mesurée sur les substrats naturels et à certaines périodes les peuplements sont déstructurés; un minimum de
0,97 bits.cell $^{-1}$ est noté en été 1982 à la station amont (fig. 15). Au travers des valeurs prises par les moyennes mobiles de l'indice IPS nous observons une tendance à leur augmentation au cours des 13 années d'étude (fig. 16), ce qui - en se référant à ces supports artificiels - tendrait à illustrer une amélioration sensible de la qualité de l'eau. Concernant plus particuliè- 
Indice Biotique

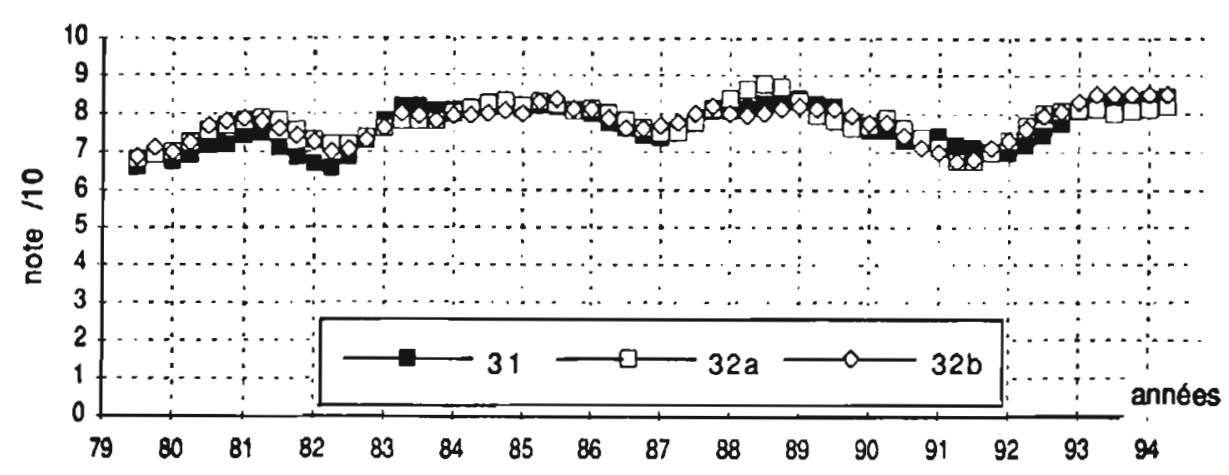

IOBG

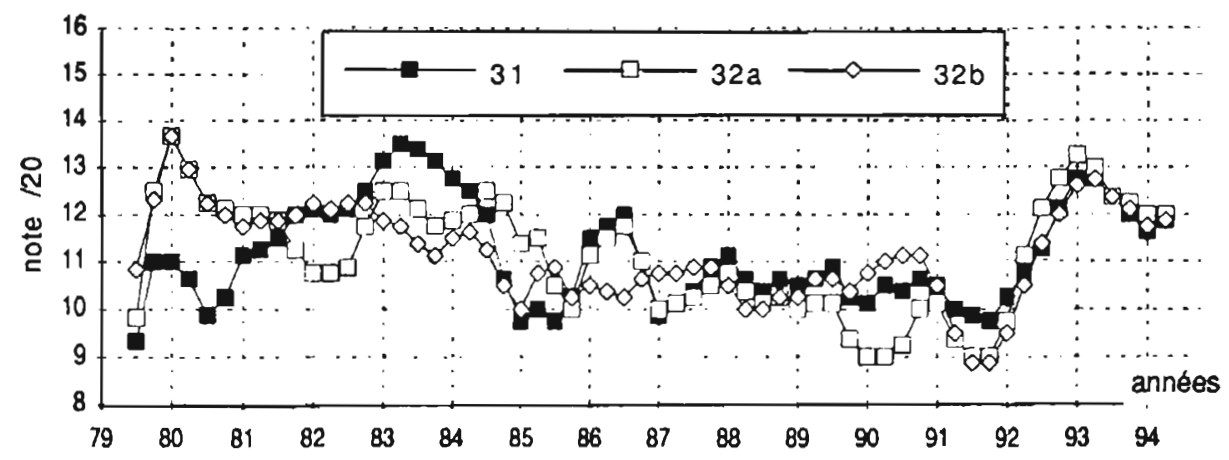

Fig. 17. - Variations des IB et des IQBG (moyennes mobiles) aux stations amont $\left(3_{1}\right)$, aval immédiat $\left(3_{2} a\right)$ et aval éloigné $\left(3_{2} b\right)$.

Fig. 17. - Variations in IB and IQBG biotic index (moving averages), measured upstream (3 $\left.\mathbf{3}_{1}\right)$, immediately after the power plant $\left(3_{2} a\right)$ and more downstream $\left(3_{2} b\right)$.

rement l'influence de la centrale, il n'y a pas de différence significative entre les stations tant pour l'indice IPS que pour l'indice CEC. Cependant, l'indice CEC révèle une différence entre le site amont et le site le plus aval de 1986 à 1991, avec des valeurs significativement supérieures en aval (fig. 16, tab. V).

\subsection{Suivi écologique des macroin- vertébrés benthiques}

Les indices biotiques, dont la note 10 reflète une qualité optimale de l'eau, révèlent des fluctuations importantes selon les années (fig. 17); les valeurs moyennes sont de 7,6-7,7 et 7,7 de l'amont à l'aval. La qualité de 
Tableau VI. - Valeurs minimale, moyenne et maximale des données macroinvertébrés. Résultats du test de Wilcoxon des valeurs appariées.

Table VI. - Minima, mean and maxima values of the different components in macroinvertebrate populations and Wilcoxon test (paired data).

MACRO INVERTEBRES

31

32 a

$32 b$

$\begin{array}{ll}\text { minımum } & 0.22 \\ \text { midimism: } & 3.20 \\ \text { moyerne } & 1.7\end{array}$

Disersıté Ephéméropteres

minimum

maximuin

moyenne

minimum

maximum

moyenne

3.20

.71

0.23

3.55

1.81

22

71

Test de Wilcoxon

31.32 a

$31-32$ b

$32 a-32 b$

$\begin{array}{lr}\text { ns } & p<0.001 \\ \text { ns } & p<0.001 \\ \text { ns } & n s\end{array}$

$I_{i}: 0$

IOBG

\section{Trichopiéres}

0.36

1.86

1.21

0.32

1.84

1.04

0.15

1. 14

1.03
4.5

6.0

9.5

18.0

$4.0 \quad 7.0$

$9.5 \quad 18.0$

$\begin{array}{ll}7.7 & 11.2\end{array}$

$\begin{array}{rr}4.0 & 7.0 \\ 9.5 & 18.0 \\ 7.6 & 11.1\end{array}$

$7.7 \quad 11.1$ l'eau se dégrade durant les années sèches, avant de s'améliorer à nouveau en année normale ou pluvieuse, quelle que soit la station étudiée. Après de fortes variations printanières de 1979 à 1986 , les IQBG, pour lesquels la note 20 est retenue comme critere de qualité optimale, prennent des valeurs plus stables entre 1987 et 1992, puis nous retrouvons une série de fluctuations (fig. 17). En référence aux résultats bruts, l'amplitude de ces fluctuations demeure cependant faible par rapport à la période antérieure à 1986. Les différences entre stations ne sont pas significatives, quels que soient les indices (tab. VI).
Le peuplement en Ephéméroptères et en Trichoptères est loin d'atteindre le degré d'organisation des diatomées, il est vrai que seule une partie de la vie de ces organismes se déroule dans l'eau. La diversité spécifique des Ephéméroptères dont le maximum atteint 3,55 bits. ind ${ }^{-1}$ varie autour de 2 bits.ind $^{-1}$ pour la période 1979-1987, plus faible ensuite et jusqu'en 1992, elle reprend des valeurs moyennes analogues à celle observées en début de suivi à partir de l'été 1992, quelles que soient les stations prospectées; il n'y a pas de différences significatives entre stations (fig. 18, tab. VI). 


\section{Ephéméroptères}

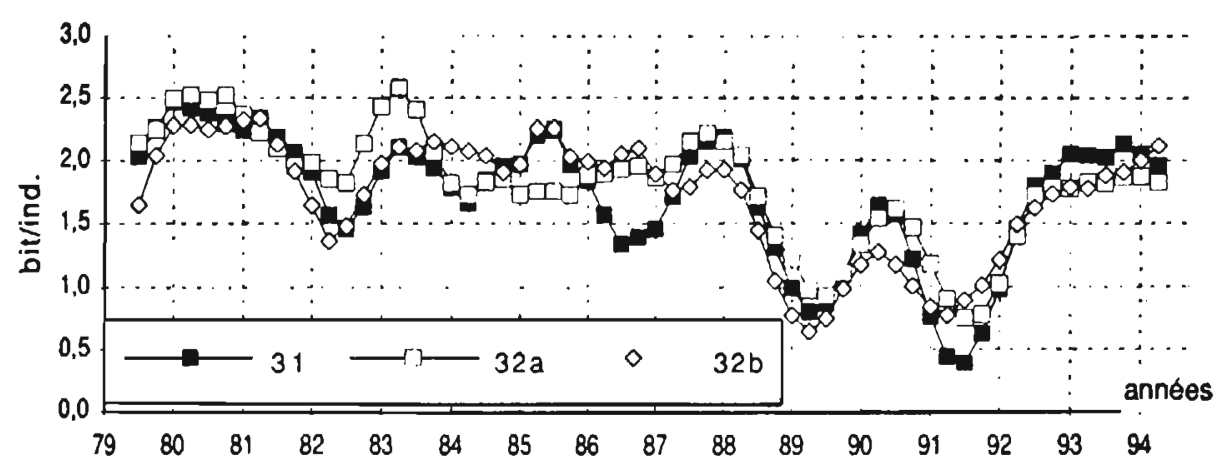

Trichopteres

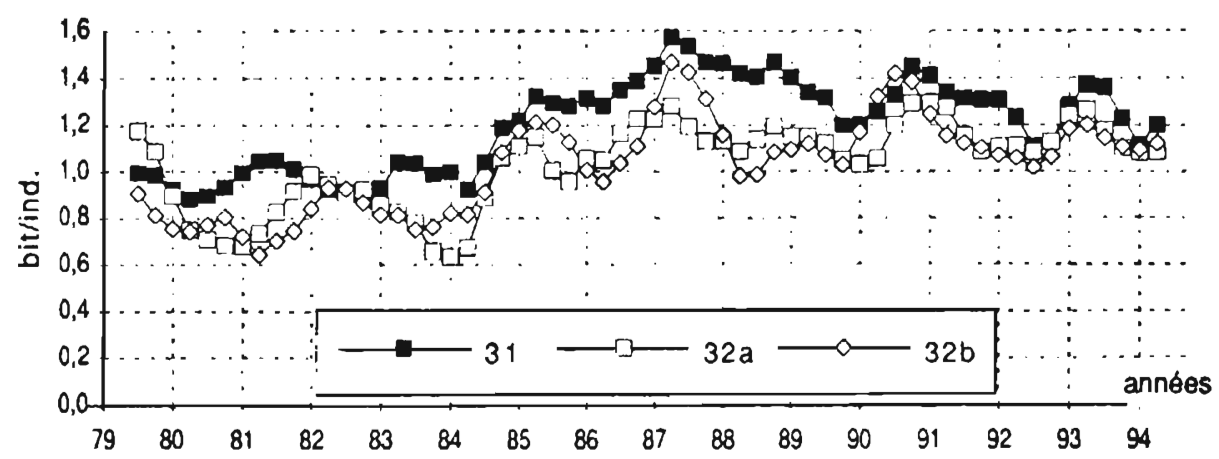

Fig. 18. - Variations de la diversité des Ephéméroptères et des Trichoptères (moyennes mobiles) aux stations amont $\left(3_{1}\right)$, aval immédiat $\left(3_{2} a\right)$ et aval éloigné $\left(3_{2} b\right)$.

Fig. 18. - Variations in specific diversity of Ephemeroptera and Trichoptera index (moving averages), measured upstream $\left(3_{1}\right)$, immediately after the power plant $\left(3_{2} a\right)$ and more downstream $\left(3_{2} b\right)$.

La diversité des Trichoptères collectés dans le milieu est dans l'ensemble encore plus faible que celle des Ephéméroptères (tab. VI). Là encore, comme pour les IQBG (1986) et pour la diversité des Ephéméroptères (1987), nous observons une rupture: les valeurs, particulièrement faibles $\left( \pm 0,8\right.$ bits.cell $\left.^{-1}\right)$ entre 1979 et 1984 , augmentent à partir de 1985 pour os- ciller autour de 1,2 bits.cell $^{-1}$ (fig. 18). Les moyennes mobiles sont respectivement de 1,2 de 1,04 et de 1,03 bits.cell $^{-1}$ aux stations amont et aval; elles illustrent une tendance régulière à une diversité plus forte en amont, par rapport aux deux stations aval, avec une différence significative entre la station amont et les deux stations aval ( $p<0,001$, tab. VI). 


\section{DISCUSSION}

Le site de Dampierre-en-Burly est étudié depuis 1977 dans le cadre des études de surveillance des sites électronucléaires du territoire français. De l'état de référence dressé au cours de deux années hydrologiques atypiques (1977-1978), nous retiendrons que la végétation riveraine demeure bien diversifiée, avec des groupements végétaux caractéristiques des différents niveaux du fleuve (bien que légèrement affectée par le relèvement du niveau des eaux en amont du seuil de la centrale). Grâce au matériel organique provenant de l'amont, il se développe une quantité non négligeable d'organismes planctoniques et benthiques qui sont adaptés aux flux d'eau irréguliers du fleuve, ce qui en référence à la typologie de Vannote et al. (1980) nous autorise à situer le secteur de Dampierre-en-Burly en taille d'ordre $>6$, au regard également des écarts de température journaliers relevés sur le site et de la grande diversité biotique que nous avons observée. Cela sous entend, une faible diversité relative des composés organiques solubles et des rapports "production/respiration" et "carbone organique particulaire/fines particules de carbone organique" faibles, dans ce secteur du fleuve qui est d'ordre 8. Les microorganismes accomplissent une autoépuration efficace dans ces eaux eutrophes, tandis qu'un abondant plancton végétal est associé à une faune rotiférienne diversifiée. II s'agit d'eau cyprinicoles. Cependant il convient de garder en mémoire que cette étude de référence s'est effectuée sous des conditions climatiques d'autant plus atypiques, qu'elles succédaient à une année de sécheresse exceptionnelle.

Les résultats de l'étude à long terme nous permettent de dégager, à partir des moyennes mobiles des données recueillies de 1979 (1982) à 1994, les caractéristiques générales de ce secteur du fleuve.

En dépit des fortes fluctuations du régime hydraulique, où alternent années sèches (1980 à 1982, puis 1989 à 1991) ou pluvieuses (1984 et 19871988), années hydrologiques normales (1984-1985-1986 étant des années de référence), les oscillations des différentes variables et de leurs amplitudes annuelles reflètent la dynamique fluviale, avec ses crues et le développement saisonnier de ses communautés vivantes qui, bien diversifiées globalement, contribuent à maintenir la stabilité temporelle de cette partie eutrophe de l'hydrosystème Loire, au niveau du site électronucléaire de Dampierre-en-Burly. En effet, certains paramètres présentent d'importantes variations (oxydabilité, matières en suspension, $\mathrm{pH}, \mathrm{DBO}_{5}$, ammoniaque, nitrates, phosphates, silice, densité et biomasse algale), en liaison avec les variations de débits et avec l'activité photosynthétique estivale.

Les organismes qui se sont adaptés aux contraintes écologiques du fleuve reflètent la diversité des ressources et des habitats. Dans ce secteur, lumière, éléments nutritifs, vitesse du courant ne limitent pas la 
croissance des populations algales qui sont denses, avec des maximums de densité $>200.10^{6}$ cell. I $^{-1}$. Les indices de diversité $>4,5$ bits sont, seIon Frontier \& Pichod-Viale (1991) exceptionnels et associés à des "échantillons de grande taille de communautés complexes"; en milieu courant, des valeurs de 4,54,6 bits.cell $^{-1}$ ont été reportées pour des communautés de diatomées vivant sur des substrats sableux (Sundbäck, 1984; Cook \& Whipple, 1982). Sur le site de Dampierre-en-Burly, la diversité spécifique des Bacillariophycées benthiques atteint 4,80 bits. cell- $^{-}$. Nous avons là une illustration des potentialités d'adaptation de ce type de peuplements; il est certain que ces algues, dépourvues d'organites de locomotion, adaptées à des conditions d'éclairement limité sont favorisées dans le potamon des fleuves par des mouvements modérés de l'eau, induits au niveau des fonds.

Les macroinvertébrés, à durée de vie beaucoup plus longue, ne paraissent pas doués dans ce secteur des mêmes potentialités d'adaptation. La diversité spécifique des Ephéméroptères et en particulier celle des Trichoptères demeure particulièrement faible, au regard de celle des communautés atgales : échantillonnage limité aux zones de bordure, sensibilité aux substrats et à la vitesse des courants, cycle de vie plus complexe (émergences), compétition pour la place et la nourriture, prédation par les poissons etc. sont autant de variables explicatives qu'il faut garder en mémoire.
Peut-on déceler depuis 1977 une évolution de la qualité de l'eau? II est certain qu'en 17 ans les activités inhérentes à la présence humaine n'ont fait que s'amplifier, mais au-delà des fluctuations, nous n'avons pas observé de tendance à l'amélioration ou à la dégradation de la qualité physicochimique des eaux. Est-ce à dire que les mesures de protection de la ressource en eau ont permis de maintenir le degré de pollution existant sans l'aggraver? L'application des directives de la loi sur l'eau de janvier 1992 devrait permettre d'en améliorer la qualité.

Si les variables abiotiques reflètent les variations du régime hydraulique, les organismes étudiés dans le cadre de cette étude sont-ils de meilleurs indicateurs? Forte en début d'étude, la richesse spécifique des microalgues planctoniques a diminué jusqu'en 1986, avant de réaugmenter progressivement à partir de 1987, pour reprendre en 1994 les valeurs observées en 1982. Après des valeurs particulièrement fortes en 1983, puis une diminution, la diversité spécifique du périphyton déposé sur les substrats naturel tend à augmenter à partir de 1986. Les valeurs de l'IPS des populations colonisant les substrats naturels (fortes en début d'étude, puis minimales en 1984) augmentent progressivement tout le long de l'étude; cette tendance est confirmée par les résultats de l'IPS issus de l'étude des peuplements déposés sur les supports artificiels. Une tendance à l'augmentation de la diversité spécifique des Trichoptères parait amorcée. 
A partir de quelle échelle de temps peut-on parler d'étude à long terme, au regard la stabilité de cet hydrosystème fluvial? Ce travail est extrait d'une synthèse réalisée par les auteurs en 1992, à la demande d'Electricité de France. En nous basant sur un suivi de 10 années, nous avions observé des tendances, très nettement mises en évidence par les moyennes mobiles, telle une tendance à l'augmentation de la diversité des algues périlithiques sur les supports naturels, manifeste jusqu'en 1991 (cf. fig. 13), ou encore la diminution des valeurs de I'IQBG et de la diversité des Ephéméroptères (effectives l'une et l'autre jusqu'en 1992, cf. fig. 17 \& 18). Cette tendance s'est avérée infirmée par l'ajout des données de 3 années supplémentaires.

Cette étude révèle également des ruptures qui paraissent indépendantes des variables abiotiques et des processus biologiques saisonniers. Une augmentation de la diversité spécifique des Trichoptères se produit à partir de 1985. A partir de 1986, nous observons d'importants changements, au niveau spécifique, parmi les Bacillariophycées planctoniques. Après des valeurs saisonnières très fluctuantes jusqu'en 1986, nous assistons de 1987 à 1992 à une stabilisation des variations saisonnières des IQBG, simultanément à la déstructuration du peuplement d'Ephéméroptères, déstructuration qui persiste jusqu'en fin d'étude. Comment expliquer les nombreuses valeurs atypiques relevées pour l'année 1992 (qui pourtant ne se démarque pas au point de vue typo- logique), avec une richesse spécifique algale plus faible dans le secteur amont de référence, avec un indice CEC plus important, avec le départ d'une nouvelle phase d'instabilité des valeurs de I'IQBG, avec une augmentation de la diversité des Ephéméroptères? Dans une revue consacrée à I'utilisation des variables biologiques comme outils de gestion, Khalanski \& Souchon (1993) constatent un phénomène analogue sur les site du Bugey où des discontinuités apparaissent sur la série chronologique des concentrations en chlorophylles planctoniques et sur la série chronologique des IQBG. II est certain que le fonctionnement de ce secteur du fleuve est étroitement intriqué aux processus qui se déroulent sur son bassin versant et que des processus retard peuvent modifier le fonctionnement de cet hydrosystème.

Concernant l'influence de la centrale, les écarts entre les stations sont liés à divers processus. Une légère augmentation de la température et du $\mathrm{pH}$ se produit à l'aval immédiat de la zone des rejets, tandis que conductivité et $\mathrm{NO}_{3}$ diminuent. De place en place, le ralentissement du courant induit une accumulation du matériel en suspension; une partie de ce matériel remué au niveau du seuil lui-même, le long duquel s'étalent les rejets, contribue à l'augmentation des MES à l'aval immédiat; ceci peut être amplifié par une production primaire locale plus importante. Les écarts entre amont et aval sont également inhérents à l'hétérogénéité naturelle du milieu, la partie immédiatement en 
amont du seuil étant plus étranglée et le fleuve s'étalant en aval. En période de basses eaux, et comme en témoigne l'analyse des variables témoins des processus de production, la plus ou moins grande étendue des secteurs lentiques induit un développement du potamoplancton qui se dilue ensuite dans les eaux du fleuve. Les teneurs en oxygène dissous et en silice augmentent progressivement de l'amont à l'aval, à l'inverse des teneurs en éléments nutritifs qui diminuent globalement plus en aval, et de la légère régression des Bacillariophycées. L'étude des organismes producteurs suggère les processus mis en cause; des eaux plus calmes et un léger réchauffement favorisant le développement des Chlorophycées, plus thermophiles que les Bacillariophycées. En outre, les algues sont soumises à la pression de broutage des herbivores; ainsi, en 1995, nous avons observé le lien étroit entre le développement de fortes densités de rotifères et la régulation des communautés algales (Lair \& Reyes-Marchant, 1997), autres causes des variations amont aval qui dépendent de la périodicité et de l'intensité des crues estivales et de la sévérité des étiages.

Quels sont les outils de gestion qui se sont avéré les mieux adaptés à ce type d'études? Nous pouvons dire que globalement aucune perturbation inhérente au fonctionnement de la centrale n'affecte la structure des communautés de microalgues planctoniques et benthiques. II s'avère, comme nous l'avions évoqué dans la partie méthodologie, que les indices diatomiques, basés sur un inventaire spécifique, conduisent à détecter des différences amont aval que la complexité des processus mis en cause n'autorise pas à expliquer en totalité. Les indices biotiques ne permettent pas de déceler de différences entres stations; les limites de ce type de méthodologie, largement illustrées par des mises au point méthodologiques successives, sont conceptuelles et inhérentes à l'échelle de perception utilisée (taxons). En effet, dès que l'on passe au niveau spécifique, des différences apparaissent, dont la baisse de la diversité des Trichoptères en aval.

\section{CONCLUSION}

A l'échelle de nos observations, les résultats obtenus au moyen des indices diatomiques (indice IPS), ou des indices de diversité spécifique (Trichoptères) traduisent urie amélioration de la qualité de l'eau, amélioration non perceptible au vu des variables physico-chimiques largement influencées par le régime hydrologique du fleuve et par les activitès métaboliques des organismes. Concernant plus particulièrement l'influence de la centrale, celle-ci est liée à la présence de la retenue de l'eau d'amené, manifeste au regard de certaines variables abiotiques et du développement des communautés algales et des Trichoptères, aussi bien qu'aux caractéristiques morphodynamiques de ce secteur de fleuve. Nous retiendrons deux choses: il paraît illusoire, à l'échelle de temps que nous avons 
considérée, de prédire ce que pourrait être l'avenir, en se basant sur des données passées, seul un suivi régulier autorise à faire des constats. II s'avère indispensable, lorsqu'il s'agit de suivre des processus biologiques de choisir l'espèce comme niveau de perception, ce qui limite l'utilisation de certains indicateurs biologiques à l'observation de processus plus globaux.

\section{RÉFÉRENCES BIBLIOGRAPHIQUES}

Admiraal W., Breebaart L., Tubbing G.M.J., Van Zanten B., De Ruijter Van Sterveninck E.D. \& Bijkerk, 1994. Seasonal variation in composition and production of planktonic communities in the lower River Rhine. Freshwat. Biol. 32 : 519-531.

Aguesse P., 1968. Etat biologique des eaux de la Loire en aval et en amont de la Centrale de Saint-Laurent des Eaux. Rapport EDF.

Amosse A., 1932. Diatomées de la Loire inférieure. Bull. Soc. Nat. Ouest, 5 : 1-57.

Cazaubon A., Rolland T. \& Loudiki M. 1995. Heteogeneity of periphyton in French Mediterranean rivers. Hydrobiologia, 300/301: 105-114.

C.E.M.A.G.R.E.F., 1982. Étude des méthodes biologiques d'appréciation quantitative de la qualité des eaux. Rapport Q.E. Lyon- A.F. Bassin Rhône-Méditeranée-Corse, $281 \mathrm{p}$.

Chessel D. \& Dolédec S., 1992. ADE Sofware. Multivariable Analyses and Graphical Display for Environmental Data. Version 3.3 User's Manual. Ecologie des Eaux Douces et des Grands Fleuves. URA CNRS 1451. Université Claude Bernard Lyon I, 69622 Villeurbanne cedex.

Cook L.L. \& Whipple A.. 1982. The distribution of edaphic diatoms along envi- ronmental gradients of a Louisiana salt marsh. J. Phycol. 18 : 64-71.

Corillion R., 1957. Les Charophycées de France et d'Europe Occidentale. Bull. Soc. Sci. Bretagne, NS. 32, 499 p.

Coste M., 1978. Sur l'utilisation des diatomées benthiques pour l'appréciation de la qualité biologique des eaux courantes. Thèse Biol. Végét. Univ. Besançon, $150 \mathrm{pp}$.

Coste M., 1990 - Programmes diatomées, notice d'utilisation succinte pour IBM PC. XT et compatibles. CEMAGREF Bordeaux - Div. qualité des eaux, 10 $\mathrm{p}+$ progr

Coste M., 1994. Sur l'utilisation des diatomées dans le diagnostic biologique de la qualité des eaux courantes - intérêt et limites des indices. Les variables biologiques: des indicateurs de l'état de santé des écosystèmes aquatiques. Séminaire national, Paris, 136152.

Dam H. Van., 1982. On the use of measures of structure and diversity in applied diatom ecology. Nova Hedwiga, Beih. 73: 87-115.

Décamps, H. \& Naiman R.J., 1989. L'écologie des Fleuves. La Recherche $20: 310-319$.

Des Cilleuls J., 1929. Le phytoplancton de la Loire et de ses affluents dans la région saumuroise. Intern. Rev. Ges. Hydrobiol., u. hydrog. Leipzig, $143 \mathrm{p}$.

Descy J.P., 1975. Étude quantitative du peuplement algal benthique en vue de l'établissement d'une méthodologie d'estimation biologique de la qualité des eaux courantes. Application au cours belge de la Meuse et de la Sambre et à la Somme. Univ. Liège, 180 p.

Descy J.P. \& Coste M., 1988. Utilisation des diatomées benthiques pour l'évaluation de la qualité des eaux courantes. C.E.M.A.G.R.E.F. Bordeaux, $24 \mathrm{p}$.

Descy J.P. \& Coste M., 1989. Application d'un nouvel indice diatomique (indice C.E.E.) au réseau national de Bassin Rhône-Méditérranée-Corse. Rap- 
port Agence Rhône-MéditérranéeCorse, $86 \mathrm{p}$.

Elwood J.W., Newbold J.D., O'Neill R.V., and Van Winkle W., 1983. Resource spiraling: an operational paradigm for analysis lotic ecosystems. In TD Fontaine and S.M. Bartell Ed. Dynamics of lotic ecosystems. Ann Arbor Science, Michigan USA, 3-28.

Friedrich G. \& Viehweg M., 1984. Recent developments of the phytoplankton and its activity in the Lower Rhine. Verh. Internat. Verein. Limnol. 22 : 2029-2035.

Frontier S., 1976. Utilisation des diagrammes rang-fréquence dans l'analyse des écosystèmes. Bull. Ecol., 8 : 445-464.

Frontier S. \& Pichod-Viale D., 1991. Ecosystemes: structure, fonctionnement, évolution. Collection d'écologie 21, Masson, Paris, $392 \mathrm{p}$.

Gay C., 1995. Indice Biologique Global Normalisé. IBGN NFT 90-350. Guide technique. Minist. Envt. Agences Eau, CSP, $69 \mathrm{p}$.

Huet M., 1954. Biologie, profils en long et en travers des eaux courantes. Bull. Fr. Pisc. $175: 41-53$.

Hynes H.B.N., 1970. The ecology of running waters. Liverpool University Press, $555 \mathrm{p}$.

Hynes H.B.N., 1975. The stream and its valley. Verh. Internat. Verein. Limnol. $19: 1-15$.

I.D.E. Environnement, 1993. Etude bibliographique des méthodes biologiques d'évaluation de la qualité des eaux de surface continentales. Étude Inter Agences $\mathrm{N}^{\circ} 35$ (3 volumes).

Khalanski M. \& Souchon Y., 1993. Quelles variables biologiques pour quels objectifs de gestion? Les différentes grilles de lecture des bioindicateurs en fonction des objectifs, des types d'impact aux différentes échelles spatio-temporelles. In Les variables biologiques: des indicateurs de l'état de santé des écosystèmes aquatiques. Séminaire national, Paris, 49-101.
Lack T.J., 1971. Quantitative studies on the phytoplankton of the rivers Thames and Kennet a reading. Freswat. Biol., 1: 213-224.

Lair N., 1980. The Rotifer fauna of the river Loire (France) at the level of the nuclear power plants. Second Intern. Rotifers Symposium, Gent, Belgium. Hydrobiologia, 73 : 153-160.

Lair N., Millerioux E. \& Restituito F, 1978. Examen physicochimique et répartition du plancton de la Loire en période d'étiage (été 1976) au niveau de la centrale nucléaire de St-Laurent-des-Eaux. Cahiers d'hydrobiologie de Montereau, $6: 53-80$.

Lair N. \& Oulad Ali H., 1990. Grazing and assimilation rates of natural populations of planktonic Rotifers Keratella cochlearis, Keratella quadrata and Kellicottia longispina living in an eutrophic lake. Hydrobiologia, 194 : 119-131.

Lair N., Pihan J.C. \& Nourrisson M., 1980. Conception et principaux résultats des études hydrobiologiques effectuées sur diftérents sites électronucléaires. Rev. Gén. Nucléaire. 1: 31-44.

Lair N. \& Sargos D., 1981. Dynamique des populations planctoniques en Loire moyenne. Ann. Stat. Biol. Besse-enChandesse, $15: 60-114$.

Lair N. \& Sargos D., 1993. A 10 years study in the middle course of the River Loire. I - Patterns of change in hydrological, physical and chemical variables at the sites of nuclear power plants, in relation to algal biomass. Hydroécol. Appl. 5: 1-27.

Lair N. \& Reyes-Marchant P., 1997. The potamoplancton of the middle Loire: the role of the "moving littoral" in downstream transfer of algae and rotifers. Hydrobiologia, 356: 33-52.

Magurran A.E., 1988. Ecological Diversity and its measurement. Croom helm, London.

Moss B. \& Balls H. 1989. Phytoplankton distribution in a floodplain lake and river system. II. Seasonal changes in the phy- 
toplankton communities and their control by hydrology and nutrient availability. J. Plankton Res. 11: 839-867.

Nisbet M. \& Vernaux J., 1970. Composantes chimiques des eaux courantes. Discussion et proposition de classes en tant que bases d'interprétation des analyses chimiques. Ann. Limnol. 6: 161-190.

Oudin C., 1990. Modélisation de l'eutrophisation en Loire. Modèle POLUPA. La Houille Blanche, 3/4: 195-206.

Pantle R. \& Buck, H., 1955. Die biologische uberwachung der Gewasser unddie Darstellung der Ergebnisse. Gas. und. Wasserfach., 96: 604 p.

Pielou E.C., 1975. Ecological diversity. Wiley, New-York, $165 \mathrm{p}$

Pourriot R., Royer G. \& Peltier M., 1972. Prolifération de Rotifères épiphytes et pollution thermique dans la Loire. Bull. français Pisc., 244 : 111-118.

Reyes-Marchant P., 1993. - Impact des alevins de gardon (Rutilus rutilus, L.) sur les communautés planctoniques littorales. Modélisation du fonctionnement trophique du lac d'Aydat. Thèse, Université Blaise Pascal de ClermontFerrand, 181 p. +50 annexes.

Rott E., 1991. Methodological aspects and perspectives in the use of periphyton for monitoring and protecting rivers. In Whitton B.A., Rott E. \& Friedrich G., 1991. Use of algae for monitoring rivers. Proceedings of an International Symposium. STUDIA Studentenförderungs-ges. m.b.H. Innsbruck, 193 p.

Round F.E., Crawford R.M. \& Mann D.G., 1990. The Diatoms, Biology \& Morphology of the genera. Cambridge Univ. Press, $747 \mathrm{p}$.

Rumeau A. \& Coste M., 1988. Initiation à la systématique des diatomées d'eau douce, pour l'utilisation pratique d'un indice diatomique générique. Bull. Fr. Pêche piscic. 309: 1-69.

Schoeman F.R. \& Haworth E.Y., 1986. Diatoms as indicators of pollution. Report on a workshop in Proc. of the 8 th Internat. Diatom. Symp. Paris Aug. 84. O. Koeltz Publ. Koenigstein, 772-776.

Sommer U., 1988. Growth and survival strategies of planktonic diatoms. In C.D. Sandgren, Growth and reproductive strategies of freshwater phytoplankton, 261-315.

Sundbäck K., 1984. Distribution of microbenthic chlorophyll-a and diatom species related to sediment characteristics. Ophelia, Suppl. 3 : 229-246.

Tuffery G. \& Vernaux J., 1967. Méthode de détermination de la qualité biologique des eaux courantes C.E.R.A.F.E.R. Paris, 4.

Vannote R.L., Minshall G.W., Cummins K.W., Sedell J.R. \& Cushing C.E., 1980. The river continuum concept. Can. J. Fish and Aquat. Sci., $37:$ 130-137.

Verneaux L. \& Faessel B., 1976. Note préliminaire à la proposition de nouvelles méthodes de détermination de la qualité des eaux courantes C.E.M.A.G.R.E.F., Paris, $20 \mathrm{p}$.

Verneaux J., 1977. Biotypologie de l'écosystème "eau courante". Déterminisme approché de l'appartenance typologique d'un peuplement ichtyologique. C. R. Acad. Sci. Paris 284 , série D : $675-678$

Whitton B.A., Rott E. \& Friedrich G., 1991. Use of algae for monitoring rivers. Proceedings of an International Symposium. STUDIA Studentenförderungges. m.b.H. Innsbruck, 193 p.

Winner J.M., 1975. Zooplankton. In River Ecology, Ed. Whitton B.A. Blackwell, Oxłord, 155-169.

Wonnacott T.H. \& Wonnacott R.J., 1991. Statistique. Economie - Gestion Sciences - Médecine, $4^{e}$ édition (trad. trançaise). Economica, $909 \mathrm{p}$.

Woodiwiss, 1964. Biological system of stream classification used by the trent river board. Chem. Indust. 14 : 443447. 